\section{The Multiple Self-Aspects Framework: Self-Concept Representation and Its Implications}

Personality and Social Psychology Review I5(I) 3-27

(C) 20II by the Society for Personality and Social Psychology, Inc.

Reprints and permission:

sagepub.com/journalsPermissions.nav DOI: I0.1 I 77/10888683 I037 I I0 I http://pspr.sagepub.com

(S)SAGE

\author{
Allen R. McConnell'
}

\begin{abstract}
The multiple self-aspects framework (MSF) conceives of the self-concept as a collection of multiple, context-dependent selves. From this perspective, five principles are derived, addressing issues such as how context activates particular regions of selfknowledge and how self-relevant feedback affects self-evaluations and affect. Support for these principles is discussed. Furthermore, the MSF advances several novel predictions, including how active self-aspects filter one's experiences and perceptions, how the impact of chronic accessibility is more circumscribed than previously realized, and how self-concept representation modulates the experience of affect. In addition, the MSF helps integrate isolated lines of research within several diverse literatures, including self-regulation, stability and variability for the self, the integration of others into the self-concept, and several individual difference factors as well. Overall, the current work speaks to issues of relevance to several subdisciplines in psychology (e.g., cultural, developmental, personality, social) interested in the self, providing conceptual and methodological insights.
\end{abstract}

\title{
Keywords
}

self, identity, social cognition, self-regulation

Indisputably, "the self" is one of the most central topics in psychology, with far-ranging implications for social interactions (e.g., Baumeister, 1998), personality (e.g., Robins, Norem, \& Cheek, 1999), developmental processes (e.g., Howe, Courage, \& Edison, 2003), culture (e.g., Markus \& Kitayama, 1991), and memory (e.g., Kihlstrom, Beer, \& Klein, 2003), to name just a few. Yet how self-concepts are represented is not well understood. In fact, in a seminal article on self and memory, Greenwald and Banaji (1989) concluded that "the self's structure has not yet been well described" and that "much of the work on delineating the self as a knowledge structure remains to be done" (p. 52). In the more than two decades since the publication of their conclusion, there is still no consensus on the self's structure. In this article, a framework for how the self is represented in memory is outlined and its implications for understanding behavior are explored.

It is notable that although psychologists have identified process-based accounts for how people understand and represent information about individuals and groups (e.g., N. H. Anderson, 1971; Asch, 1946; McConnell, Sherman, \& Hamilton, 1994; Srull, 1981; Srull \& Wyer, 1989), our perspective of how selfrelevant knowledge is organized in memory is far less developed. Most view self-concept as the content of what people believe to be true about themselves (Baumeister, 1998; Forgas \& Williams, 2002), but many important questions remain. For example, is this content about one self or many? If it is for many selves, how are they represented? How does the organization of self-knowledge influence affect, self-evaluation, and behavior? How do we integrate and reconcile different perspectives and findings about the self? What are the ramifications for how we conduct research on the self? In the current work, I tackle these questions by proposing that the self is represented in an associative network. From this approach, five principles about self-concept representation are forwarded. I then review the evidence supporting these principles, discuss new hypotheses and psychological insights derived from this view of the self, and finally integrate a number of disparate findings and theories in the literature.

\section{Prelude}

A great deal of research examining the self in the psychological literature views it as a relatively unitary entity (for critiques, see Kurzban \& Aktipis, 2007; Spencer-Rodgers, Williams, \& Peng, in press). Although many researchers offer prefaces to the contrary and then focus on a limited domain of the self,

\footnotetext{
'Miami University, Oxford, OH, USA
}

Corresponding Author:

Allen R. McConnell, Miami University, Department of Psychology, Oxford, OH 45056

Email: mcconnar@muohio.edu 


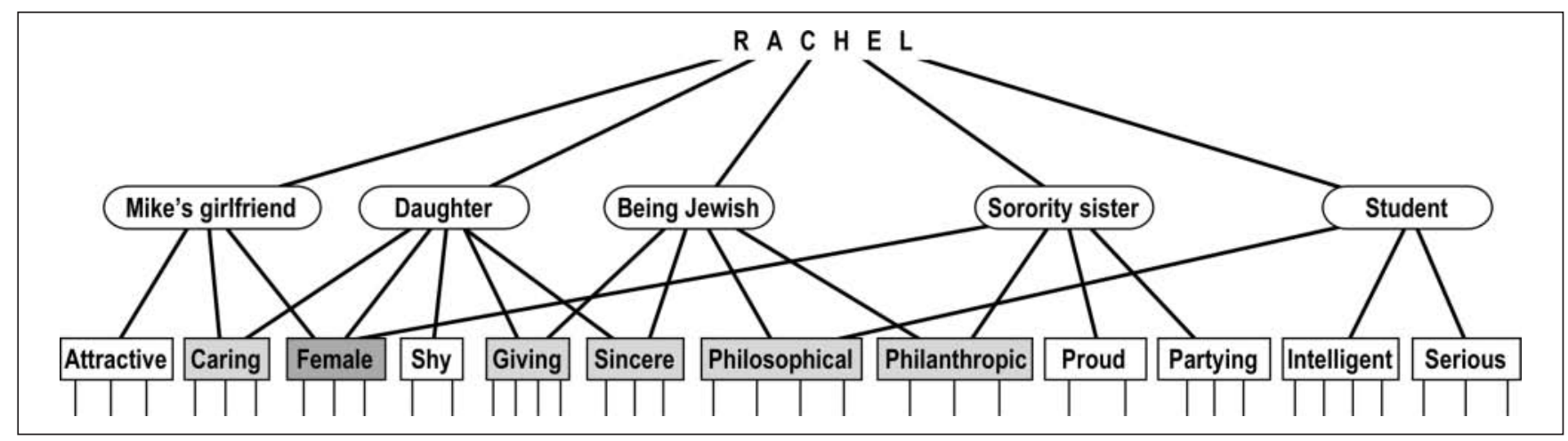

Figure I. Hypothetical self-concept for a person named Rachel with five self-aspects (the ovals) and associated attributes (the rectangles) Note: Shaded attributes are those associated with more than one self-aspect.

the impression derived from the literature suggests that there is a single self. For example, research on topics such as selfesteem, self-theories, self-clarity, and cognitive dissonance typically focuses on overarching evaluations of one's sense of self-worth, lay beliefs regarding the stability of one's personality, certainty in one's beliefs about the self, and consistency of one's beliefs and actions, respectively (e.g., Campbell et al., 1996; Cooper \& Fazio, 1984; Dweck, 1999; Swann, ChangSchneider, \& McClarty, 2007; Tice, 1993). In other words, most work at least implicitly assumes there is a broad, overarching self to be evaluated, understood, and reconciled. In contrast, the current perspective explores the value of explicitly considering how the self-concept is composed of multiple, contextually activated selves.

Of course, some researchers have proposed that people possess multiple selves (e.g., Higgins, 1987; Markus \& Nurius, 1986; Roberts \& Donahue, 1994). Although these important lines of work acknowledge a multifaceted self, they do not articulate how these selves are organized in memory. Furthermore, each of these literatures typically considers a particular type of multiple self (e.g., an ought self, a feared self) without any attempt to integrate the diversity of multiple selves outlined across different literatures. For example, those interested in understanding personality and symbolic interaction have considered variability for the self across a fixed set of social roles (e.g., Block, 1961; Donahue, Robins, Roberts, \& John, 1993; Serpe, 1989). Although social roles are undoubtedly an important component of the self, there are certainly other aspects of the self that transcend roles.

Indeed, many psychologists have posited that a number of facets compose the self beyond just social roles. For example, some have focused on specific facets of the self, such as one's academic, social, and emotional self-concepts (e.g., Marsh \& Craven, 2006; Shavelson, Hubner, \& Stanton, 1976). Others, however, have emphasized the private, public, and collective aspects of the self (e.g., Breckler \& Greenwald, 1986; Triandis, 1989). Similarly, Brewer and colleagues (e.g., Brewer \& Gardner, 1996; Sedikides \& Brewer, 2001) proposed that the self has personal, relational, and collective levels. More broadly, some researchers have focused on the interplay of social identities and the self, with perspectives ranging from viewing social identities as relatively independent of the self (e.g., Turner, Oakes, Haslam, \& McGarty, 1994) to seeing them as infused into the self-concept (e.g., Deaux, 1993) to viewing them as evolving across a number of stages (e.g., Amiot, de la Sablonnière, Terry, \& Smith, 2007). Even though a number of important theoretical distinctions have been forwarded regarding these levels of the self, with a few exceptions (e.g., Smith, Coats, \& Walling, 1999; Trafimow, Triandis, \& Goto, 1991) little work has considered their organization in memory. Furthermore, no perspective has been advanced that can assemble the diversity of perspectives on the self (e.g., social roles, private selves, relational selves) into a comprehensive framework.

Finally, a number of scholars have considered the role of culture in understanding the self, with much of this work advocating for a relatively unitary sense of self for members of individual-centered cultures (e.g., Fiske, Kitayama, Markus, \& Nisbett, 1998; Markus \& Kitayama, 1991; Triandis, 1989). Specifically, it has been argued that in independent cultures (e.g., North America, Western Europe), the self is defined as relatively separate from social context, unitary, and consistent in nature (compared to a more interdependent, connected self in more collectivists cultures). But is this really the case? Although the current perspective certainly agrees that important cultural differences in self-construal exist, it contends that the self even in independent cultures is far from being unitary, consistent, and separate from social context.

\section{The Multiple Self-Aspects Framework}

In the current work, a formulation of self-concept structure is advanced, the multiple self-aspect framework (MSF). Figure 1 illustrates the self-concept of a person named Rachel, who will serve as an example throughout the article to illustrate key points. In this framework, self-knowledge is represented as a 
Table I. Five Principles of the Self Derived From the Multiple Self-Aspects Framework

I. The self is a collection of multiple, context-dependent self-aspects.

2. Self-aspects are associated with personal attributes, which become more accessible when the self-aspect is activated and vice versa.

3. Overall affect reflects the evaluation of one's self-aspects weighted by their accessibility, and thus feedback about a self-aspect will affect general affective states to the extent that the information has implications for one's evaluation of that self-aspect.

4. Feedback about a self-aspect influences evaluations of other self-aspects that share greater attribute associations.

5. The impact of information pertaining to a specific attribute on overall affect increases as the number of self-aspects associated with the attribute increases.

network of distributed nodes. Each node is associated with other nodes, which vary in their accessibility (Bruner, 1957; Collins \& Loftus, 1975; Hayes-Roth, 1977; Higgins, 1996; Smith \& Queller, 2004). At any given moment, the activation of different associative regions within this network gives rise to context-modulated contributions to perception and behavior. The MSF is certainly not the first description of self-concept representation (e.g., DeSteno \& Salovey, 1997; Kihlstrom \& Klein, 1994; Marsh \& Craven, 2006; Mischel \& Shoda, 1995), and in fact it arose from our earlier work on self-complexity (e.g., McConnell et al., 2005; Renaud \& McConnell, 2002; Schleicher \& McConnell, 2005), which historically was interested in explaining who experiences greater emotional variability in the face of feedback and stress (e.g., Linville, 1985, 1987; Rafaeli-Mor \& Steinberg, 2002). The MSF evolved from our previous work when it became clear that the depiction of the self-concept in the self-complexity literature was underspecified and incomplete. This led to developing a more comprehensive account of self-concept representation grounded in self-complexity but extending into new areas to explain a broader array of phenomena. In this article, I identify five principles derived from the MSF (see Table 1) and review their support. Although the MSF is not the first attempt to describe how the self-concept is organized in memory, there is considerable evidence in support of this particular depiction of the self. And more important, the current work demonstrates that the specific arrangement of self-knowledge described by the MSF generates novel predictions and serves heuristically as a valuable scaffolding to integrate a number of diverse literatures on the self that typically reside in isolation from each other.

Principle 1: The self is a collection of multiple, contextdependent self-aspects.

Although Rachel has general affective experiences (e.g., mood states) and an overarching awareness of herself as a person derived from reflexive consciousness and self-awareness across time (Baumeister, 1998; James, 1890), the MSF contends that her behaviors and experiences are primarily directed by more distinct self-representations. Specifically, her self-concept is viewed as a collection of multiple, context-dependent selfaspects stored in memory that serve to guide her behavior. These self-aspects (the ovals in Figure 1) reflect meaningful contextual aspects of her life and are idiosyncratic in nature. In her case, they include roles (e.g., daughter, student), social identities (e.g., being Jewish, sorority sister), and social relationships (e.g., Mike's girlfriend). For other people, self-aspects might also consist of goals (e.g., who I want to be), affective states (e.g., being moody), and behavioral situations (e.g., meeting new people). Thus, self-aspects are broad organizing concepts, capturing roles (e.g., Roberts \& Donahue, 1994), goals (e.g., Higgins, 1997), private and public selves (e.g., Triandis, 1989), and relational and collective identities (e.g., Brewer \& Gardner, 1996). Their idiosyncratic nature reflects one's experiences (e.g., influence of meaningful others, immersion in cultural contexts, experiences in the environment), and these self-aspects function to guide one's understanding and behavior.

Returning to our example, at any given moment, a variety of contextual inputs (e.g., environmental settings, social interactions, mental simulation) serve to activate relevant selfaspects, which in turn organize Rachel's ongoing experiences and direct her actions. That is, self-aspect activation results from the dynamic inputs and constraints of one's goals, actions, and cognitions as the self moves through the environment (e.g., Niedenthal, Barsalou, Winkielman, Krauth-Gruber, \& Ric, 2005; Smith \& Semin, 2004). Furthermore, self-aspects vary in their accessibility, with some self-aspects being more accessible (and thus, more likely to guide behavior) because of recent or frequent use (Bargh \& Pratto, 1986; Higgins, Rholes, \& Jones, 1977). For example, when waking up on a particular morning, Rachel's “student" self-aspect is more likely to guide her initial behavior if she spent the previous evening in the library studying, whereas her "Mike's girlfriend" self-aspect is more likely to direct her actions if she had been on a date with Mike instead. In most circumstances, one self-aspect will be relatively more activated, directing context-appropriate perception and action effectively (e.g., Bruner, 1957; Hasher \& Zacks, 1988; Shallice, 1972). For instance, even if Rachel had just been on a date, entering a classroom would likely increase the accessibility of her "student" self-aspect to such a level that it would be the primary determinant of her behavior. Yet if the class was a course on Jewish studies, it is likely that both her "student" and her "being Jewish" self-aspects would have increased accessibility, leading to their joint influence on her behavior.

Principle 2: Self-aspects are associated with personal attributes, which become more accessible when the self-aspect is activated and vice versa. 
The MSF proposes that each self-aspect is associated with a number of attributes in the network of self-knowledge. These descriptive attributes (the rectangles in Figure 1) can include traits (e.g., shy), behaviors (e.g., philanthropic), physical characteristics (e.g., attractive), affect (e.g., proud), and social categories (e.g., female), among others. Attributes can be quite idiosyncratic and derived from numerous sources, including culturally transmitted knowledge (e.g., Geertz, 1973; Shweder et al., 1998), feedback provided by others (e.g., Cook \& Douglas, 1998; Mead, 1934), inferences drawn from one's own behavior (e.g., Bem, 1967; Fazio, 1987), experiences moving through one's environment (e.g., Neisser, 1991, 1993), and physically experienced or simulated bodily states (e.g., Niedenthal et al., 2005; Wilson, 2002). Attributes are the products of a number of exemplars (e.g., personally experienced events, behavioral episodes), which are depicted by the vertical lines underneath each attribute. Although it is assumed that exemplars give rise to attributes, any given exemplar can influence multiple attributes, and it may take many exemplars to produce an attribute. For example, Rachel's sense of being philanthropic may have been developed after several specific exemplars (e.g., her rabbi extolling the virtues of charity at her synagogue, her donating blood to the Red Cross, her chairing a fund-raiser for her sorority). Following a number of such events, these exemplars can lead to more global and abstracted self-representations (Kihlstrom \& Klein, 1994; Klein, Loftus, Trafton, \& Fuhrman, 1992).

Although self-aspects reflect organizing contexts that are extrapersonal (e.g., when I am, where I am), attributes are the descriptive features exhibited by the individual in those contexts that are intrapersonal (e.g., what I am, how I am). In some cases, attributes may be uniquely associated with one self-aspect (e.g., attractive), whereas other attributes may be associated with multiple self-aspects (e.g., philosophical). Thus, attributes exist in an associative system, forming a broad, intricate network of self-knowledge. Although any concept in theory could serve as a self-aspect or as an attribute depending on how it is construed by the individual, the MSF views attributes as representing descriptive information about the individual (e.g., Rachel's qualities as a sorority sister might be quite unique from any other member of her sorority) and self-aspects as representing the context binding that individuating information together (for a similar discussion regarding the distinction between social categories and traits, see Bodenhausen, Macrae, \& Sherman, 1999). That is, the adjectives people use to describe their qualities (e.g., shy, philanthropic) will generally be their attributes, whereas the nouns that establish contexts binding those attributes (e.g., Mike's girlfriend, student) typically reflect their self-aspects. Although this distinction may seem somewhat vague, people can easily and reliably report their self-aspects and attributes, and their idiosyncratic self-perceptions have predictive utility for understanding their affect, behaviors, and self-regulatory activities (to be discussed).

Because the attributes associated with one's self-aspects can be quite differentiated, one's behavior may be markedly different as a function of which self-aspects are more accessible. For example, Rachel's behavior on a given evening might be quite different based on whether she is in the library (where her student self-aspect would be activated) or at a Panhellenic function (where her sorority sister self-aspect would be activated). These distinct contexts would trigger different selfaspects, which through spread of activation would actuate associated attributes that in turn can evoke different traits, emotions, goals, perceptions, and actions. Thus, one's behavior will be quite different across contexts to the extent that one's self-aspects are associated with relatively unique attributes, yet one will reveal considerable stability within contexts.

Activation between self-aspects and attributes is assumed to be bidirectional. As noted above, context can activate a self-aspect, which in turn increases the accessibility of related attributes. As a result, Rachel might be shy and giving when with her parents but a proud partier with her sorority sisters. On the other hand, the activation of particular attributes should increase the accessibility of associated self-aspects as well. Thus, drinking beer at a work-related picnic might increase the accessibility of her "sorority sister" self-aspect (even though the event does not involve her sorority), which in turn could lead her to act in ways consistent with her Panhellenic identity at the picnic. This notion that context and behavior can mutually prime each other and affect a broad range of activities (e.g., one's goals, one's judgment) is consistent with many contemporary perspectives on social cognition (e.g., Chartrand \& Bargh, 2002; Dijksterhuis \& Nordgren, 2006; Ferguson, 2007; Smith \& Semin, 2004).

Principle 3: Overall affect reflects the evaluation of one's self-aspects weighted by their accessibility, and thus feedback about a self-aspect will affect general affective states to the extent that the information has implications for one's evaluation of that self-aspect.

The MSF proposes that self-concept structure plays an important role in shaping general affective states (e.g., mood, state self-esteem). These affective experiences are of interest not only as phenomenological events but also because they are important in directing behavior. For example, diffuse affect influences the extent to which people process information effortfully (e.g., Schwarz \& Clore, 2007), reveal creativity in problem solving (Gasper, 2003), render causal judgments (e.g., Keltner, Ellsworth, \& Edwards, 1993), vary in reports of their physical health (e.g., Salovey, Detweiler, Steward, \& Bedell, 2001), use stereotypes (e.g., Bodenhausen, Kramer, \& Suesser, 1994), and recall events (e.g., Bower \& Forgas, 2001). Thus, understanding the relation between self-concept structure and affective experiences is quite important.

Within the MSF, it is assumed that Rachel's current affective state is derived from evaluations of her five self-aspects. If her self-aspects are activated at roughly equivalent levels, her mood should reflect the average appraisal of her five self-aspects. 
On the other hand, to the extent that a self-aspect is more dominant in its activation, its influence on her general affect should grow in proportion to its relative accessibility. This assumption has important implications. Consider, for example, that Rachel's boyfriend telephones and tells her that she is a wonderful girlfriend. Although such positive feedback is likely to enhance her general affective state (e.g., increase positive mood), the MSF articulates a process through which this occurs. First, his phone call should provide a context that increases the accessibility of her "Mike's girlfriend" self-aspect, augmenting its contribution to her overall affect. Second, to the extent that his comment enhances her evaluation of that now highly accessible self-aspect (i.e., she views her "Mike's girlfriend" selfaspect more positively following his call), it should have an especially strong influence on improving her general affect. Similar outcomes would be expected for negative events too. In statistical terms, changes in appraisals of relatively accessible self-aspects should mediate how self-relevant feedback affects one's overall affect.

It is important to note that Principle 3 anticipates that feedback about particular self-aspects should have a greater impact on general affective experiences. For instance, some selfaspects should be relatively more chronic or more central to the self, and thus their influence should be greater than less chronic or less central self-aspects. Frequently encountered contexts should result in highly accessible self-aspects, which should reveal greater activation even in the absence of recent use (Higgins, King, \& Mavin, 1982). Because the MSF assumes that more accessible self-aspects make greater contributions to general affect, feedback about chronic self-aspects (which by definition are highly accessible) should be quite consequential. It is also likely that some self-aspects are more central to the self(Rosenberg, 1979; Sedikides, 1995). Although centrality has been operationalized in a number of ways, including reports of importance to the self (e.g., Boldero \& Francis, 2000) and ratings of self-descriptiveness (e.g., Verplanken \& Holland, 2002), how centrality for the self is represented in memory has received little attention. The MSF sheds light on this issue. To the extent that more central self-aspects are more accessible in general or share attributes with other self-aspects, the propagation of self-relevant feedback through the associative network as outlined in the MSF should result in information related to central self-aspects having a greater impact on the self. Thus, the MSF anticipates a number of ways in which self-aspects can differ (e.g., chronicity, centrality), but its focus on representation accounts for how feedback about these self-aspects is especially weighty.

Principle 4: Feedback about a self-aspect influences evaluations of other self-aspects that share greater attribute associations.

Based on the spread of activation within the MSF, one can consider a relatively intriguing possibility: Self-aspect feedback may not only shape general affective states (Principle 3) but also influence appraisals of other self-aspects with shared attributes. For instance, if Rachel's boyfriend remarks that she is a wonderful girlfriend, it may not only enhance her evaluation of her "Mike's girlfriend" self-aspect but also increase the positivity of her sense of her attractiveness, her caring, and her femininity because all three attributes are associated with her dating self-aspect. And via spreading activation, the positivity transduced from his comment to these attributes may also enhance appraisals of other self-aspects associated with these attributes. As an example, her "daughter" self-aspect is composed of five attributes, two of which are also associated with her "Mike's girlfriend" self-aspect. Thus, her evaluation of herself as a daughter may grow more positive in proportion to the ratio of attributes it shares with the self-aspect associated with the self-relevant feedback. However, her boyfriend's comment may not affect appraisals of her student self-aspect because there is no associative overlap of attributes. Hence, the MSF anticipates that feedback may not only change general affect and evaluations of the related self-aspect but also influence appraisals of other self-aspects based on the particular associative structure of one's self-concept.

Principle 5: The impact of information pertaining to a specific attribute on overall affect increases as the number of self-aspects associated with the attribute increases.

In the previous example, we considered the impact of Rachel's boyfriend providing feedback about a self-aspect (i.e., she is a wonderful girlfriend). Yet sometimes feedback pertains to people's attributes. For instance, imagine that Rachel's boyfriend told her that she's very attractive. Although his comment would probably increase her evaluation of her "Mike's girlfriend" self-aspect, it has no implications for other self-aspects. On the other hand, consider that he complimented Rachel's femininity. Positive feedback about this particular attribute is pertinent to three self-aspects, and thus its potential to affect her overall affect should be relatively greater, all things being equal, than a comment praising her attractiveness. Thus, as attributes are associated with more self-aspects (whose evaluations, in turn, contribute to general affective states), feedback about them should be especially influential for general affect. In statistical terms, the proportion of self-aspects in one's selfconcept associated with a particular attribute should mediate how feedback about it changes overall affect.

\section{Support for the MSF Principles}

Principle I. The foundational principle of the MSF is that the self-concept is a collection of multiple, context-dependent self-aspects. Although some programs of research acknowledge the existence of multiple selves (e.g., Higgins, 1987; Markus \& Nurius, 1986; Marsh \& Craven, 2006; Roberts \& 
Table 2. Types of Self-Aspects Generated by Participants With Examples and Their Prevalence

\begin{tabular}{llc}
\hline Type & \multicolumn{1}{c}{ Examples } & $\begin{array}{c}\text { Percentage of } \\
\text { self-aspects }\end{array}$ \\
\hline Situations & When in a crowded situation, meeting new people & 18 \\
Relationships & With my boyfriend, with my family & 17 \\
Roles & Daughter, as a student & 16 \\
Affective & When l'm freaking out, my positive qualities & 13 \\
True selves & The real me, who I really am & 13 \\
Goal & Who I ought to be, who l'm afraid l'll become & 10 \\
Temporal & The old me, my future me & 5 \\
Public & How others see me, the public me & 2 \\
Alone & When I am alone, by myself & I \\
Others & & 5 \\
\hline
\end{tabular}

Note: $N=140$.

Donahue, 1994), these lines of research have, typically, only considered particular types of multiple selves (e.g., one's ideal selves, five common social roles, one's academic self-concept) in a restricted manner. Other work in the self-complexity literature (e.g., Linville, 1985; Renaud \& McConnell, 2002) and in the self-concept compartmentalization literature (e.g., Showers, 1992; Showers \& Kling, 1996) has allowed people to generate their own self-aspects but only by putting selfdescriptive traits into groups as a means to produce selfaspects. Thus, to evaluate Principle 1 more fully without imposing any constraints (e.g., asking participants to consider specific roles, having them build self-aspects from collections of traits), it would be useful to observe the self-aspects that people spontaneously generate in an open-ended fashion.

To this end, 140 undergraduate participants at Miami University were asked to identify the "meaningful aspects of their lives" to assess their self-aspects. This participant population is interesting to consider because members of an individualcentered culture should, based on prevailing thinking, be relatively more inclined to report having unitary selves. Asking participants to generate self-aspects in an open-ended manner, without specific instructions or examples, can provide some insights into perceptions of their own, idiosyncratic self-aspects. Although such reports have limits (e.g., introspective access, self-presentation), they have been used effectively in a number of studies to capture accessible self-knowledge that is predictive of behavior (e.g., Linville, 1985; Showers, 1992).

On average, these participants listed 4.23 self-aspects. As shown in Table 2, in order of prevalence, people reported social situation self-aspects, relationship self-aspects, social role selfaspects, affectively laden self-aspects, true selves, goal-related self-aspects, temporally oriented self-aspects, public selves, and alone self-aspects (with others being too unique to characterize). It is interesting to note that although these students lived in an independent culture and were free to report having just one self-aspect, very few did (less than 3\%). Moreover, of the remaining participants, only $43 \%$ reported having a "true self" among a collection of other self-aspects. Thus, the prevalence of a unitary self-concept was extremely low, and those who reported having a "true self" viewed it as only one self-aspect among many others.

Although people may report having several self-aspects, it is possible that there is tremendous overlap in the attributes associated with each self-aspect, making distinctions among them less important. For example, one could view oneself as being "shy" as a daughter, "shy" as a sorority sister, and "shy" as a student and thus reveal great consistency across many identifiable contexts. To consider this possibility, another study asked 339 Miami University undergraduates to identify their self-aspects (as in the previous study) and then to ascribe attributes that describe themselves in each self-aspect from a list of 40 traits (half positive, half negative) commonly used by college students to describe themselves (Showers, 1992). In this self-concept description task, they were told to use as many or as few of the attributes as they wanted, that they could reuse attributes in multiple self-aspects, and that they did not have to use all of attributes provided. On average, they listed 4.43 self-aspects and used 22.59 of the 40 attributes provided in describing themselves across their self-aspects. Although $42 \%$ of the attributes used appeared in more than one selfaspect (suggesting some continuity across self-aspects), 58\% of the attributes used were only associated with one self-aspect. Thus, most people reported having multiple self-aspects that were largely described by unique (instead of recurring) attributes. Yet there was also some redundancy in the attributes associated with some self-aspects, and in accordance with the MSF, this is important for the operation of MSF principles that rely on spread of activation across the self network to produce several outcomes of interest. Overall, these data demonstrate that people report a number of relatively diverse self-aspects.

Principle 2. A key assumption of the MSF is that social context activates a relevant self-aspect, which increases the accessibility of the attributes associated with it. In other words, only the attributes associated with the relevant region of the selfknowledge network should become activated. Although this 
principle seems intuitive, empirical support for it has only recently been provided.

In one study, Hugenberg and Bodenhausen (2004) had undergraduates who were members of the Greek system (i.e., campus sororities) participate in a study where some had their sorority self-aspect activated by a questionnaire asking them to reflect on their sorority identity (a control condition had no such priming). Next, all participants completed a lexical decision task in which some words referred to Greek life (e.g., keg, party). Lexical decision tasks ask participants to judge as quickly as possible whether strings of letters presented are words or nonwords, with faster judgments of target words indicating their greater accessibility in memory. Those students whose sorority self-aspects were activated through priming were faster at judging Greek-related words in comparison to control participants. This work suggests that self-aspect-pertinent information enjoys an activation advantage; however, Hugenberg and Bodenhausen did not assess students' own idiosyncratic attributes in these self-aspects - only general knowledge broadly associated with Greek life. To provide further evidence that context activates specific self-knowledge, it would be beneficial to prime a selfaspect and observe that its specific attributes are rendered more accessible in memory.

Accordingly, McConnell, Rydell, and Brown (2009) conducted an experiment where, during an initial prescreening session, participants completed the self-concept description task described previously (i.e., reporting their self-aspects and which of 20 positive and 20 negative attributes were associated with them). Several weeks later, they returned for what seemed to be an unrelated, three-part study. In the first and third "studies," participants completed identical lexical decision tasks where the target words were the same 40 attributes provided to them during the self-concept description task completed weeks earlier. In between these lexical decision tasks, participants wrote for $5 \mathrm{~min}$ about one of their self-aspects (hereafter, the targeted self-aspect) that they listed in the self-concept description task. The writing exercise was designed to activate the targeted self-aspect, which according to Principle 2 should increase the accessibility of only those attributes idiosyncratically associated with it. Indeed, that is exactly what was obtained: Participants were relatively faster (following the priming) with lexical judgments about attributes they associated with the targeted self-aspect and not for self-descriptive attributes associated with their other self-aspects. This supports the prediction that context (in this case, instantiated by the writing exercise) activates the relevant self-aspect, which in turn increases the accessibility of attributes associated with it.

Principle 2 also anticipates that the activation of self-relevant attributes (e.g., one's traits, one's behaviors) should increase the accessibility of associated self-aspects, which in turn should direct one's perceptions and actions. At present, there is no work directly testing this bottom-up route for self-aspect activation. However, other lines of work suggest that this assumption is reasonable. For instance, Mussweiler (2006) demonstrated that behaviors (e.g., walking slowly) activate associated concepts in memory (e.g., stereotypes of the elderly) directly though the principle of ideomotor action (James, 1890; also see Bargh, 1997; Dijksterhuis \& Bargh, 2001). Similarly, work on embodied cognition has shown that actions can directly activate concepts in memory as well (Niedenthal et al., 2005). Thus, although the bottom-up route to self-aspect activation awaits demonstration, such outcomes seem likely.

Principle 3. The MSF proposes that general affective states (e.g., mood, state self-esteem) are related to the appraisals of one's self-aspects and are especially reflective of evaluations of relatively more accessible self-aspects. This principle suggests two different, testable assertions. First, all things being equal, the average evaluation of one's self-aspects should predict general affective states. Second, feedback about a specific self-aspect will increase its accessibility (Principle 2), resulting in especially strong changes in general affective experiences when the feedback influences appraisals of that self-aspect.

To assess the first assertion, 87 Miami University undergraduates completed a modified version of the self-concept description task and two different general affect measures. The self-concept description task was the same as previously described (i.e., list self-aspects and select their attributes from a list of 40 items), but after participants completed the task, they evaluated the positivity of each self-aspect listed on a scale ranging from 1 (very negative) to 7 (very positive). General affect was assessed with two commonly used measures: Rosenberg's (1965) Self-Esteem Scale and the Positive and Negative Affect Schedule (PANAS; Watson, Clark, \& Tellegen, 1988). The Self-Esteem Scale assesses general evaluative beliefs about the self (e.g., "I take a positive attitude toward myself'), and the PANAS evaluates participants' mood by asking them to indicate the extent to which they are currently experiencing 10 positive (e.g., proud) and 10 negative (e.g., distressed) affective states, which are combined to produce an index of relative positive mood (analyses conducted on the positive and negative scales separately produced similar results). To assess overall self-aspect appraisal, the mean evaluation across each participant's self-aspects was computed, which was then correlated to participants' general affective measures. As expected, those who reported more positive self-aspects also had greater self-esteem $(r=.48, p<.01)$ and more positive moods $(r=.33$, $p<.01$ ). Thus, general affective state (assessed by two different measures) was reliably related to self-aspect evaluation.

Although supportive of the first premise of Principle 3, the data are clearly limited by their correlational nature. But more intriguing is the MSF-derived prediction that feedback about a self-aspect affects general affect more strongly when it changes one's evaluation of the now-activated self-aspect. To explore this possibility experimentally, we (McConnell et al., 2009) conducted a study where participants completed the self-concept description task (including evaluations of each self-aspect generated) in an initial laboratory session. Several 
weeks later, 60 of those who reported having student and dating self-aspects returned for a second session where they completed a bogus personality test (see McConnell, Rydell, \& Leibold, 2002). Specifically, participants' descriptions of a series of inkblots were "scored" by a computer, resulting in either positive (e.g., "you are in the top $10 \%$ of college students in terms of having fulfilling romantic relationships") or negative (e.g., "you are in the bottom $10 \%$ of college students in terms of having fulfilling romantic relationships") feedback about either their dating or student self-aspect (i.e., their targeted self-aspect). After receiving this feedback, participants' mood was assessed (using the PANAS), and they once again evaluated the positivity of each of their self-aspects on the same scale used in the first experimental session. Not surprisingly, the feedback (positive or negative) affected mood and evaluations of the targeted self-aspect, indicating that it was viewed as credible information. But more important with respect to Principle 3, changes in evaluations of the targeted self-aspect mediated the impact of feedback valence on mood. For example, negative feedback about one's student self-aspect lowered one's mood, and this drop in mood could be accounted for by how much the feedback reduced positive appraisals of the student self-aspect. Thus, changes in general affect (in this case, mood) were driven by how self-relevant feedback modified views of the activated self-aspect, underscoring how overarching affective experiences are shaped by how feedback affects the self at the level of self-aspects.

Principle 4. The aforementioned study (McConnell et al., 2009) reported additional analyses that evaluated Principle 4, which proposes that feedback about a self-aspect not only affects general affective experiences (Principle 3) but also can influence evaluations of other self-aspects that share common attribute associations. Recall that participants received feedback about a targeted self-aspect, but they provided evaluations (both prior to the experimental feedback and afterward) for all of their selfaspects, including nontargeted self-aspects (i.e., those not directly related to the feedback). Thus, one can examine, in the wake of feedback about the targeted self-aspect, how appraisals of nontargeted self-aspects changed as well. And more specifically, the detailed structure of the self outlined by the MSF anticipates that the impact of feedback about a targeted self-aspect on evaluations of nontargeted self-aspects should be stronger when more attributes associated with the nontargeted self-aspects are also associated with the targeted self-aspects. Thus, for each nontargeted self-aspect, an overlap index capturing the proportion of its attributes that were also associated with the targeted self-aspect was computed. Indeed, consistent with Principle 4, those nontargeted self-aspects that showed the strongest changes in evaluation following feedback were those that had greater attribute overlap with the targeted self-aspect. In other words, self-aspect feedback not only changed perceptions of that selfaspect and affected overall affect (as discussed for Principle 3) but also influenced evaluations of other self-aspects that shared greater associations with the same attributes.
Principle 5. In addition to predictions about the impact of selfaspect feedback, the MSF anticipates that feedback about a self-relevant attribute will affect overall affect, especially as the number of self-aspects associated with it increases because general affect is determined by the evaluative inputs of selfaspects. In support of this hypothesis, we conducted yet another experiment where participants completed the self-concept description task before responding to a bogus inkblot-based personality test (McConnell et al., 2009). However, instead of receiving feedback about a self-aspect (e.g., one's dating selfaspect), they received feedback about an attribute that was used in their self-concept description task (e.g., outgoingness, intelligence). The feedback about this attribute was either positive (i.e., top $10 \%$ with respect to the attribute) or negative (i.e., bottom $10 \%$ with respect to the attribute) in valence. Following the experimental feedback, participants' mood was assessed using the PANAS. Not surprisingly, participants had more positive moods following positive feedback than following negative feedback. But more important for the MSF, this effect was mediated by the proportion of self-aspects associated with the feedback-relevant attribute. In other words, feedback about an attribute had more of an impact on general affect when its spread of activation implicated more self-aspects.

\section{New Insights Derived From the MSF}

The Impact of Self-Aspects Is Pervasive: Invisible Context. The MSF suggests that one's perceptions and actions, at any given moment, are directed by only a subset of self-knowledge. For instance, changes in mood were determined by the extent to which self-relevant feedback altered appraisals of currently activated self-aspects (McConnell et al., 2009). This perspective raises intriguing questions about how life events, in general, affect the self. As previously noted (also see Swann et al., 2007), most research on the self assumes that feedback affects some global sense of self. However, the MSF suggests that it is more likely that feedback has its primary impact on activated self-aspects and that broader consequences (e.g., affective experiences, changed appraisals of other self-aspects) are propagated by spread of activation through an individual's self-concept structure. In other words, self-relevant feedback is typically situated in a particular context, and its wider ramifications are determined by self-aspects and their organization in the self-knowledge network.

More generally, this suggests that the accessibility of selfaspects can affect behavior in a number of ways, and this has important implications for how we measure self-related constructs. For example, when assessing undergraduate participants' lay theories about the nature of their personality as being relatively malleable and changeable (e.g., Dweck, 1999), it is possible that such measurements may be biased by participants' beliefs about their student self-aspects (even in the absence of specific instructions to consider this aspect of their life) because they typically enter the laboratory on an academic campus to 
take part in a class-related experiment, and thus it is likely that their student self-aspect is highly accessible during the experiment. Although self-theory (e.g., Dweck, 1999; Dweck \& Leggett, 1988) proposes that lay beliefs can exist for specific qualities (e.g., Is one born intelligent or is it developed?), attempts to measure general lay beliefs may be strongly influenced by beliefs about activated self-aspects.

It is important to note that the current analysis is not a criticism of self-theories research per se (indeed, these issues apply to work from our lab; e.g., McConnell, 2001; Renaud \& McConnell, 2007), but rather this reflects a broader point about how the relative activation of a subset of self-knowledge may produce an invisible context (i.e., the inadvertent influence of accessible self-aspects) in many situations and may affect experiments designed to capture general knowledge about the self. But more generally, invisible context may filter any perception or action, not just self related. For example, Rachel getting off the phone with her parents (which increases the accessibility of her daughter self-aspect) might affect her perceptions of an acquaintance (e.g., viewing him as being relatively shy) or her own behavior (e.g., giving a dollar to a charitable cause when asked). Although work has shown that priming traits can influence social perceptions (e.g., Higgins et al., 1977), the current analysis suggests that self-aspect activation may produce similar outcomes as well. And relatedly, the activation of close others (who may themselves be represented in one's self-aspects, such as "Mike's girlfriend") may influence self-perceptions through similar contextual effects (Hinkley \& Andersen, 1996).

Also, many studies in the literature (e.g., Berglas \& Jones, 1978; Linville, 1985; Renaud \& McConnell, 2002) involve undergraduate participants completing a task in an academic laboratory (i.e., their student self-aspect is activated) and receiving feedback suggesting poor academic or intellectual performance (i.e., feedback that is student self-aspect relevant), and its subsequent impact on affect and behavior is assessed. It is quite possible that they would be less affected if the feedback did not implicate qualities important to their student self-aspect in a context where their student self-aspect is highly accessible and influential in directing behavior. Although these and other similar studies assume that feedback about one's student selfaspect is powerful because of its centrality (undoubtedly true in many cases), it may also be the case that part of its potency is derived from the fit between the feedback and one's most accessible self-aspect. Similar concerns, both theoretical and methodological, have been expressed by those who study socially situated cognition (e.g., Smith \& Semin, 2004, 2007) and the influence of context on self-reports (e.g., Norenzayan \& Schwarz, 1999). Future research should explore how invisible contexts operate and evaluate their theoretical and methodological implications.

Chronicity May Not Be So Chronic. When considering the data presented earlier, it is interesting that although many attributes listed by participants were associated with only one selfaspect, some were not. In examining the data from the 339 participants presented earlier, average individuals had at least one attribute appear in $69 \%$ of their self-aspects. Attributes that appear in such a large proportion of one's self-aspects are probably relatively chronic in nature (Higgins et al., 1982; Markus, 1977). Interestingly, the prevalent view of chronicity is that some attributes (typically assumed to be traits, though this premise is probably more appropriate for independent cultures than for interdependent cultures; Cousins, 1989; J. G. Miller, 1984, 1986; Shweder \& Bourne, 1984) are always accessible and thus always influence perceptions of the self (e.g., Markus, 1977) and of others (e.g., Bargh, Bond, Lombardi, \& Tota, 1986). For instance, someone who is chronic for "honesty" should evaluate himself or herself and others based on the implications of "honesty" because of its heightened accessibility in memory. In sum, past work on chronicity (and on schematicity) has assumed that these concepts guide interpretation and behavior in all contexts.

When considering the example of Rachel, some attributes (those in gray in Figure 1) are associated with multiple selfaspects. For example, attributes such as traits (e.g., caring), group attributes (e.g., female), and behaviors (e.g., philanthropic) that are represented in multiple self-aspects will be relatively more influential than attributes associated with only one self-aspect. These qualities should be more chronic because, all things being equal, attributes associated with a greater number of self-aspects have more opportunities for activation, increasing the likelihood that the attribute will be relatively more accessible because of repeated use (Higgins et al., 1982).

An interesting corollary of the MSF is that although some attributes will be relatively chronic, they may not be germane to all self-aspects. Thus, when context activates a self-aspect that is not associated with a chronic attribute, it is less likely that the attribute itself will be especially influential, despite its general prevalence in the self-concept. As a result, the impact of chronic attributes may be more limited than previously thought. When considering the example of Rachel, although her femininity may be a relatively chronic attribute, it has no implications for her "student" self-aspect. Thus, it should not affect her behavior when she is in the role of being a student. Yet because past work on chronicity has assumed a relatively unitary self-concept (i.e., a trait is chronic for the self), existent research would anticipate that chronic attributes should influence perception and behavior in all domains. The MSF, in contrast, predicts domain specificity even for attributes traditionally considered to be chronic.

Recent work in our lab has supported this MSF-derived prediction (Brown \& McConnell, 2009b). In two different studies, participants' chronic attributes were assessed using traditional measures. For example, one of the most frequently used methods asks individuals to list traits they frequently see in others (e.g., people they like, people they dislike, people they encounter), and those that are listed initially and repeatedly are 
deemed chronic (e.g., Higgins et al., 1982). In addition to reporting their chronic traits (as solicited by traditional measures), they also completed a self-concept description task to determine which self-aspects were, or were not, associated with their chronic trait. During a subsequent experimental session, participants activated (through a 5-min writing exercise) a selfaspect that either was or was not associated with their chronic trait. Afterward, they made judgments about either themselves (e.g., speeded judgments about whether traits were selfdescriptive) or others (e.g., assessing ambiguous behaviors that could potentially be interpreted as in line with their chronic traits). In both studies, participants showed the chronicity effects previously reported in the literature (e.g., faster "me" judgments for a chronic trait, assimilating others' behaviors in line with a chronic trait) when the writing exercise primed a self-aspect associated with their chronic trait but not when the writing task primed a self-aspect not associated with their chronic trait. Thus, it appears that the outcomes associated with chronicity were observed only when a self-aspect associated with the chronic attribute was activated, indicating that chronic traits are not "always turned on."

If this position is correct, then why has past work shown broad consequences of chronic attributes? First, the MSF would anticipate that, stochastically, any given self-aspect is relatively more likely to have chronic attributes associated with it than not. Second, most studies exploring chronicity have been conducted with undergraduate students in university-based laboratories. As a result, both the assessment of chronic traits and the demonstrations of their impact probably involve the activation of the same self-aspect (e.g., one's student self-aspect), and thus a similar context exists for both the measurement of chronic attributes and the situations where their consequences are revealed, further underscoring the impact of invisible contexts.

The distribution of attributes among self-aspects may play a pivotal role in a variety of important outcomes. If we once again return to the example of Rachel, although "female" is an attribute that is associated with several of her self-aspects (and hence would be considered relatively chronic by conventional standards), it is not associated with her student self-aspect. Thus, despite the prevalence of this attribute across many of her selfaspects, her gender may be relatively unimportant for her student self-aspect. As a result, the MSF would anticipate that Rachel might be far less susceptible to stereotype threat in the classroom (Shapiro \& Neuberg, 2007; Steele, 1997) than another woman whose gender is associated with her student self-aspect even if this other person's self-concept has "female" associated with fewer self-aspects and thus (by prevailing standards) is less likely to be gender chronic. Indeed, recent work in our lab (Rydell, McConnell, \& Beilock, 2009) demonstrated that whether stereotype threat effects are revealed by women performing math problems who are aware of the cultural stereotype that "men are better than women at math" depends, in part, on which self-aspect is activated (e.g., a self-aspect related to one's gender or being a college student). That is, stereotype threat can be either experienced or forestalled based on which selfaspect is activated (also see Shih, Pittinsky, \& Ambady, 1999). Again, the MSF illustrates that many phenomena such as stereotype threat may be more nuanced than currently viewed because of how an activated self-aspect guides behavior.

The Self Is Composed of More Than Traits. Another important implication of the MSF is that it views self-relevant attributes as being composed of more than just traits. The position that trait knowledge is "the base element" of the self-concept is prevalent (e.g., Cantor \& Kihlstrom, 1987; Markus, 1977; Roberts \& Donahue, 1994), yet at the same time this approach is limiting. For example, this perspective reflects an independent cultural bias to view the self as being primarily composed of personality traits (e.g., Markus \& Kitayama, 1991; J. G. Miller, 1984; Shweder \& Bourne, 1984). More broadly, the trait approach to personality has received a great deal of criticism (e.g., Mischel, 1973; Pervin, 1994; cf. McCrae, 1994; Robins, John, \& Caspi, 1998). Operationally, many studies from different perspectives examine self-concept by asking participants to describe themselves based on traits provided to them (e.g., Linville, 1985; Roberts \& Donahue, 1994; Showers, 1992). For example, research on self-concept differentiation asks participants to endorse the extent to which they exhibit a variety of fixed traits derived from the five-factor model of personality across a fixed collection of roles (McCrae \& Costa, 1999). Greater variability in trait endorsement between roles (e.g., being outgoing with friends but not as a worker) reflects greater self-concept differentiation, which has been shown to be related to more maladaptive outcomes such as being more anxious, more depressed, and lower in self-esteem (Donahue et al., 1993).

Some of the most advanced theoretical work on selfknowledge representation has concluded that the self becomes increasingly represented by traits, instead of episodic events, as more information about the self is encountered (e.g., Klein et al., 1992; Klein, Sherman, \& Loftus, 1996). Specifically, these researchers have found support for the idea that although self-knowledge is initially exemplar based (i.e., composed of specific behavioral episodes), it becomes increasingly abstracted into trait summaries as people develop greater experience with a behavioral domain (e.g., Klein, Chan, \& Loftus, 1999; Klein et al., 1992; Klein et al., 1996).

Although we believe that self-relevant attributes are often composed of traits especially after the accumulation of a considerable number of behavioral exemplars and especially in cultures that promote independent self-construals (Markus \& Kitayama, 1991) or entity theories of personality (Dweck, 1999), other forms of self-relevant knowledge seem likely as well. For example, Carlston's (1992, 1994) associated systems theory assumes that different systems underlie visual, verbal, affect-related, and action-related information. These systems are hypothesized to produce specific forms of social representation: physical appearance (visual system), personality traits (verbal system), affective responses (affect system), 
and behavioral responses (action system). Additional types of representations result from blends of these systems (e.g., combining the visual and verbal systems gives rise to "social categories"). Work in our lab (e.g., Schleicher \& McConnell, 2005) importing associated systems theory into self-concept representation has been promising. For instance, we found that people spontaneously use a wide variety of attributes (e.g., physical appearance, emotions, behaviors) in describing their self-aspects in addition to personality traits, and this broader array of attributes provides additional utility predicting people's responses to stressful life events. In short, people view the self as composed of more than just trait attributes, and assessing self-concept with a broader constellation of attributes captures meaningful variability in predicting human behavior.

Yet another area that reveals the importance of viewing the self as composed of more than traits is work on embodiment (Niedenthal et al., 2005; Smith \& Semin, 2004). For example, there is growing evidence that sensorimotor information and proceduralized knowledge often play critical roles in developing expertise and in helping individuals to juggle cognitive demands in the environment (e.g., Beilock \& Holt, 2007; Goldin-Meadow, 2003; Kirsh \& Maglio, 1994; Wilson, 2002). As people develop extensive domain-specific information, we would anticipate that they would have self-aspects to represent this knowledge with attributes that include motoric and kinesthetic representations. For example, people with expertise in playing sports such as hockey or football, in comparison to people who do not have experience playing the sport, are faster at correctly identifying that a visually presented target item was incorporated into written descriptions of sportspecific actions when the presentation of the target item's action matched the behavior implied in the sentence than when it mismatched the behavior implied in the sentence (Holt \& Beilock, 2006). Thus, it seems that for people with considerable firsthand experience in activities, information associated with the motor actions performed in those domains is represented in memory. Although this is a relatively new area of interest, the implications of embodiment for issues ranging from social cognition (Smith \& Semin, 2004) to attitudes (e.g., Beilock \& Holt, 2007) are considerable, and their application to self-concept representation merits additional attention, especially when considering issues such as the development of expertise. Similarly, we would expect other consequences of expertise (e.g., better domain-relevant memory) to become imbued in one's self-aspects as well (e.g., Beilock, Carr, MacMahon, \& Starkes, 2002; Beilock, Jellison, Rydell, McConnell, \& Carr, 2006; Chase \& Simon, 1973; Ericsson \& Staszewski, 1989; Norman, Brooks, \& Allen, 1989). This emerging area of work reaffirms the importance of ensuring that any model of selfconcept representation considers both declarative and proceduralized knowledge about the self.

Self-Concept Structure Plays an Important Role in Affect-Based Phenomena. Several lines of work propose that affect provides a signaling cue to people with respect to their behavior. For example, a number of self-regulation theories view stronger negative affect as resulting from greater discrepancies with desired outcomes (e.g., Carver, 2001, 2003; Carver \& Scheier, 1998; Duval \& Wicklund, 1972; Higgins, 1987, 1997). More generally, mood influences the extent to which people seek information to understand their environment (e.g., Schwarz \& Clore, 1996), continue performing a task (e.g., Martin, Ward, Achee, \& Wyer, 1993), exhibit creativity (e.g., Gasper, 2003), form attributions (e.g., Sinclair, Mark, \& Clore, 1994), and scrutinize persuasive appeals (e.g., Wegener, Petty, \& Smith, 1995). Because the MSF addresses how affect is experienced, it offers insights for how a variety of important outcomes are influenced by self-concept representation.

For example, a common feature of self-regulation theories is that discrepancies with one's goal selves result in stronger negative affect, which in turn compel one to work harder to reduce the discrepancy. The magnitude of this affect is assumed to be proportionate to the absolute discrepancy (e.g., Higgins, 1987) or the degree to which one is making progress toward the goal (e.g., Carver \& Scheier, 1998). Although these factors are undoubtedly important, the MSF would also add that selfconcept representation plays a role in how discrepancy-related affect is experienced. For example, as one's discrepancyrelated self-aspect is more accessible in memory (Principle 3) or as related attributes are associated with more self-aspects (Principle 5), any affect experienced should be even stronger, increasing goal pursuit activities. Thus, the MSF proposes that self-concept organization contributes to self-regulation because the structure of one's self-concept shapes the propagation of affective experiences.

Another MSF-derived insight is that one's affect (e.g., mood, self-esteem) is shaped by how self-relevant feedback changes evaluations of the now-activated self-aspect (McConnell et al., 2009). In some ways, this finding seems reminiscent of work by Pelham and Swann (1989), who found that one's self-esteem was more related to self-conceptions held with greater certainty. From the perspective of the MSF, to the extent that greater certainty results from self-aspects that are more frequently used, those self-aspects should (all things being equal) be more activated. And based on Principle 3, evaluations of such highly accessible self-aspects should be more influential in shaping overall affect, including self-esteem. Although this explanation is admittedly tentative, the MSF suggests a mechanism to account for why some self-conceptualizations influence affect more strongly than others (e.g., Pelham \& Swann, 1989).

More broadly, the MSF provides an approach for the integration of affect with the self. The "self is more than traits" perspective of the MSF allows one to consider how attributes related to affect and emotion may be triggered by self-aspect activation. Research shows that activating emotions affects perception at a very basic level, leading to greater perceptions of similarity between stimuli related to emotions that one is 
currently experiencing (Niedenthal, Halberstadt, \& Innes-Ker, 1999). When context activates a self-aspect associated with specific forms of affect, the MSF would anticipate that subsequent information processing would be filtered by the affect associated with that self-aspect. And when self-aspects reflect one's social group memberships (e.g., sorority sister), group-specific emotions (e.g., proud) that have become associated with these group identities may be triggered (see Smith, Seger, \& Mackie, 2007). Furthermore, the bidirectional nature of the MSF predicts that activating specific emotions such as pride might lead to activating group identity self-aspects associated with these emotions.

The Development of Self-Aspects. One area that awaits additional work is expanding our understanding of how self-aspects develop. Overall, we view some self-aspects as being the product of top-down processes, whereas others are assembled in a bottom-up fashion. For example, top-down self-aspects are those transmitted from cultural knowledge (e.g., "being a married son"; Shweder \& Miller, 1985), feedback from other people (e.g., "you are a tidy person"; R. L. Miller, Brickman, \& Bolen, 1975), and pervasive stereotypes (e.g., "being African American"; Crocker \& Major, 1989). In general, these are self-aspects that "are supplied" to people from extraperson sources. On the other hand, many self-aspects are assembled in an intrapersonal, bottom-up manner based on self-perception (e.g., Fazio, 1987), experiences navigating through the environment (e.g., Neisser, 1991), and on-line integration of one's experiences (e.g., McConnell et al., 2002). Although bottom-up self-aspects may take more time to construct than top-down self-aspects (which can be conferred, in toto, to the person based on his or her place in the social order), once formed, self-aspects should serve to maintain a sense of stability within that particular context regardless of their formation.

From our perspective, there are two different but important sets of questions for which we know too little. First, what are the developmental processes involved in the production of selfconcept organization? Although there has been considerable work exploring the development of self-esteem and domainspecific competencies (e.g., Harter, 1992; Marsh \& Ayotte, 2003), there has been less work in understanding the development of self-concept representation (but see Amiot et al., 2007; Marsh \& Shavelson, 1985; Shavelson et al., 1976). For instance, Shavelson et al. (1976) posited that self-concepts are multifaceted, hierarchically organized structures that become behaviorally more variable at more specific levels. Although similar to the MSF in a number of ways, those authors forwarded a measurement instrument that assesses students' competencies in several fixed domains (e.g., peer relations, reading, math) that are of interest to educational settings. In the past 30 years, this is still how self-concept has been assessed in this literature (e.g., Marsh \& Ayotte, 2003; Marsh \& Craven, 2006). In our view, it would be beneficial to employ new techniques (e.g., the self-concept description task) to explore the development of self-concept structures in ways that are not tethered to specific domains.
A second issue of interest is understanding how self-concept structure evolves over time. For example, do self-concepts "come and go" (e.g., Rachel breaks up with her boyfriend but replaces this self-aspect with a clique of new friends that also features attributes overlapping with her daughter self-aspect), or does self-concept representation suddenly shift in its structure? At present, we really do not have many answers to these questions, but we believe that collecting developmental data will be important for improving our understanding of how the self changes.

\section{Integrating the MSF With Other Perspectives on the Self}

Self-Regulation. As previously noted, a great deal of work has focused on how the self plays a role in goal attainment (e.g., Carver, 2001, 2003; Carver \& Scheier, 1998; Higgins, 1997; Markus \& Nurius, 1986; Ryan \& Deci, 2000). Although these programs of research differ in important ways, they each propose that temporal selves (e.g., future selves, past selves) and goal selves (e.g., ought selves, feared selves) serve to guide behaviors and that discrepancies with them provide self-regulatory feedback that directs subsequent action. It is interesting that although each of these theoretical perspectives suggests having "other selves," none of them speaks to the representation of these selves. One possibility derived from the MSF is that goalrelated selves are represented as self-aspects. Indeed, the data presented in Table 2 suggest that people do spontaneously list self-aspects that are temporal and goal related in nature.

If goal-relevant selves are represented in memory as selfaspects, a number of possibilities are suggested. For example, consider Higgins's (1997) regulatory focus model, which posits that discrepancies with one's self-guides (e.g., ideal selves representing one's aspirations, ought selves reflecting one's obligations) serve to direct goal-relevant behaviors. The regulatory focus model posits not only that different self-guides exist and serve to produce particular types of emotions but also that particular types of goal-directed behaviors are initiated to reduce self-discrepancies. Specifically, reducing discrepancies with an ideal self engages a promotion focus involving the eager pursuit of successes, whereas reducing discrepancies with an ought self initiates a prevention focus that emphasizes the vigilant minimization of losses (e.g., Higgins, Idson, Freitas, Spiegel, \& Molden, 2003). Based on the MSF, we would anticipate that ideal self-aspects should be composed of a greater number of engagement-related attributes (e.g., "confident," "energetic"), whereas ought self-aspects should reveal relatively more protection-related attributes (e.g., "careful," "weary").

It is important to note that goal-relevant self-aspects are important to many literatures, including self-awareness theory (e.g., Carver, 2003), future selves (e.g., Markus \& Nurius, 1986), cybernetic theory (Carver \& Scheier, 1998), and selfdetermination theory (Ryan \& Deci, 2000). Interestingly, despite the considerable predictive utility of these theories, the 
proportion of self-aspects reported that are specifically devoted to goal selves and temporal selves is relatively small (i.e., $15 \%$ of self-aspects). Although they are undoubtedly important (e.g., one's "future doctor" self-aspect may guide one's behavior through college, medical school, and residency for many years and later become the foundation of one's professional identity), the fact that $85 \%$ of spontaneously generated selfaspects are not directly tied to goal selves and temporal selves suggests that self-regulatory activities may involve other components of the self. Perhaps there are particular, and heretofore unstudied, forms of self-regulatory behavior that might be demonstrated by those who have self-aspects that reflect affective states or abstract situations.

For instance, it is possible that many people may engage in self-regulation based on the prescriptions provided by a particular self-aspect (e.g., when in a large group situation) that guide behavior. People whose self-concepts include such self-aspects undoubtedly do so because their past experiences differ from those of people who do not (e.g., someone who feels social anxiety around others is more likely to have an "in a large group situation" selfaspect than someone who is at ease in such situations). Such a suggestion is consistent with classic research emphasizing the important role that scripts and stories play in behavior (e.g., Schank \& Abelson, 1977, 1995). However, the current analysis would suggest that such scripts may be represented in one's selfconcept and that the incorporation of such situation-specific selfaspects into self-knowledge reflects relatively more persistent goals and needs of the individual (Bargh, 1982). Although most people can describe "how to act in a large group situation," the fact that such knowledge is deemed to be a meaningful aspect of the self reflects its import to such people.

This perspective is compatible with reasoning by Mischel and Shoda (1995; also see Cervone \& Shoda, 1999), who proposed that people exhibit "if . . then ..." situation-behavior relations that account for how individuals show marked variability in their behaviors across time. Specifically, they propose that although some people exhibit variability in their actions across time, they often show consistent behaviors in particular situations. They proposed a personality system that is composed of if-then situation-behavior profiles (or person $\times$ situation interaction terms; e.g., Mendoza-Denton, Ayduk, Mischel, Shoda, \& Testa, 2001) that account for how people perceive coherence for the self while revealing variability in their actions. The MSF would incorporate such "if . . then ..." relations into one's situational self-aspects. Indeed, the prevalence of situational self-aspects indicates that the activation of a specific self-aspect by a particular context would result in situationspecific cognitions, personality characteristics, emotions, and behaviors being activated as well. Thus, the notion of "person by situation self-encoding" (e.g., Mendoza-Denton et al., 2001) is quite consistent with the MSF, and both would anticipate that such situation-specific knowledge should serve to direct one's behavior appropriately. Moreover, both perspectives anticipate that people should show sizable consistency within situations but can exhibit considerable variability across situations. Yet the MSF allows for many other forms of self-knowledge beyond situationally triggered self-aspects.

Another mechanism by which self-regulation may be achieved is through prescriptions provided by role-based selfaspects, which are often culturally constructed and transmitted. For example, Shweder and Miller (1985) provided an analysis of Hindu customs and social order (particularly among Oriyas in eastern India), observing that many roles in Hindu culture (e.g., being a woman, being a married son) stipulate rigid obligations and duties. In such cases, one's behaviors may be strongly regulated by culturally mandated self-aspects. Similar outcomes (i.e., role-based self-aspects serving to regulate action) should be revealed in cultures and organizations where members strongly subscribe to a common tradition and history. Thus, even in a relatively independent society such as the United States, "culture" exists at many levels and can supply role-based self-aspects that guide behavior, whether it is Southern views on honor-related violence (e.g., Cohen, 1998; Nisbett \& Cohen, 1996) or how Greek letter organization norms influence eating disorders and substance abuse (e.g., Landa \& Bybee, 2007; McCabe et al., 2005). Accordingly, one's "Southerner" or "sorority sister" self-aspects in the United States will encompass expectations that serve to regulate behavior. Thus, the content and sources of self-aspects may vary considerably across cultures and organizations, but their representation and functions should not.

Interplay of Consistency and Variability for the Self. A longstanding question about the self is whether it is consistent or variable (e.g., Cervone \& Shoda, 1999; DeSteno \& Salovey, 1997; Fiske et al., 1998; Markus \& Kunda, 1986). In many ways, this classic issue ties the study of the self in social psychology to many disciplines less focused on situational variability, including personality, cultural, and developmental psychology. Moreover, one can consider variability for the self at a number of levels, including whether the self is variable within contexts, across contexts, and across the life span.

From the perspective of the MSF, we would expect relative consistency for the self within contexts. Presumably, context activates self-aspects, which in turn increases the accessibility of associated attributes. Although it is possible that attributes associated with a self-aspect can change, it seems that significant revision of attributes within a self-aspect is relatively unlikely. Like any cognitive structure, self-aspects, once formed, should be relatively robust, which will ultimately serve self-consistency motives (Swann, Rentfrow, \& Guinn, 2003). That is, self-aspects should serve to guide information seeking, fill in informational gaps, assimilate ambiguous feedback to confirm preexisting self-knowledge, encourage others to view the self as consistent with one's own beliefs, and be resistant to change (e.g., Bargh, 1982; Greenwald, 1980; Markus, 1977; McConnell et al., 2002; Steele, 1997; Swann et al., 2003; Swann $\&$ Read, 1981). Although self-perception can affect views of 
the self (Salancik \& Conway, 1975), such changes are rare when one has well-developed self-knowledge (Chaiken \& Baldwin, 1981). Of course, change is possible. For example, based on Dweck's (1999) work on implicit theories, people holding more incremental views of a self-aspect might reveal greater self-aspect change than those who adopt a more entity theory perspective of that self-aspect. In general, though, we would expect relative consistency for an individual across time within the same context.

Between contexts, however, the MSF would anticipate the possibility of considerable variability for the self. From the data presented above, it is clear that people typically possess several self-aspects and that many of them are composed of relatively unique attributes. As a result, it is not surprising that one can behave quite differently in different situations. However, we anticipate that there are factors that influence the extent to which one's self-aspects will reveal variability. First, being a member of a culture that stresses people are variable (instead of consistent) should increase the likelihood of more differentiated self-aspects. Also, because self-aspects by nature reflect discrete, meaningful facets of the self, we would anticipate that, in general, those possessing more self-aspects would have more differentiated self-aspects. On the other hand, as discussed earlier, those who have attributes that are highly accessible or associated with many self-aspects should reveal greater consistency across contexts.

The issue about whether the self varies across situations reflects different perspectives on the nature of the individual. For example, personality psychologists have focused on determining an individual's stable characteristics (e.g., Pervin, 1994), whereas social psychologists have argued that people vary considerably as a function of the situation (e.g., Ross \& Nisbett, 1991). One attempt to bridge these perspectives is the position that people reveal consistency within situations but show variability across situations (e.g., Cervone \& Shoda, 1999). Indeed, the MSF endorses this perspective, arguing that the activation of self-aspects increases the accessibility of relevant personal attributes, resulting in within-context stability. On the other hand, different contexts should evoke different self-aspects, which can lead to markedly different behavior. However, the MSF also anticipates meaningful individual differences in the extent to which people exhibit differences across contexts. Primarily, people who possess fewer self-aspects or who possess self-aspects that share considerable attribute overlap with other self-aspects should reveal relatively more similarity across contexts. Thus, the nature of self-concept representation will predict whether an individual exhibits cross-situational similarity or variability. This ability to capture "for whom" variability is likely a unique strength of the MSF approach, and its emphasis on the representational structure of self-aspects allows for the prediction of which situations will, and will not, reveal similarity for a person.

One can also think about the functions of self-concept representation and its changes across the life span. Clearly, people adopt new social roles (e.g., child, student, spouse, parent) and find themselves in new contexts, thus shifts in self-concept representation should result. Moreover, in many contexts, the content of the self-concept will be influenced by establishing attributes that help to distinguish the self (especially in independent cultures) from others (e.g., optimal distinctiveness; Brewer, 1991). Thus, the content of one's self-concept will often reflect attributes that distinguish one from others in a given contexts. For example, children are more likely to use their gender when describing themselves if they live in households where their gender is in the minority (McGuire \& McGuire, 1988). Thus, Rachel is more likely to have the attribute "female" in her family-related identity (e.g., daughter self-aspect) if her siblings are mostly brothers instead of mostly sisters. Thus, the functions self-aspects serve (e.g., optimal distinctiveness) will influence the attributes associated with self-aspects, which in turn will result in context-specific expressions of one's selfdefinitions. And do self-aspects change in systematic ways across time? Although there is considerable work on developmental milestones and abilities (e.g., Kohlberg \& Kramer, 1969; Piaget, 1932), our knowledge about how self-concepts change throughout the life span is nascent (but see Amiot et al., 2007).

In addition to questions about changing content, another issue that is very germane to the MSF is whether self-concept structure reveals a developmental signature. That is, independent of the content, do people maintain the same number of self-aspects throughout their lives, or are there factors that lead to the representation of self-concept changing with the passage of time? For instance, are some people more prone to experience "emotional rollercoaster lives" because their self-concepts inherently feature attribute overlap, making feedback about any self-aspect more consequential in general? Intriguing questions such as these await future research.

Integrating Others Into the Self:Relationships and Social Identities. It is fascinating that although the self seems to, at first blush, suggest all that is isolated and unique about a person, important others are an integral part of self-knowledge. This fact is affirmed by Table 2 , which notes that the second most widely reported type of self-aspect is directed toward relationships with others. In one sense, it is not surprising that "spouse" or "with friends" self-aspects would be important to so many because the need to belong is considerable (e.g., Baumeister \& Leary, 1995; Brewer \& Gardner, 1996; Correll \& Park, 2005; Twenge, 2007). However, it is noteworthy that such relationships are freely associated with the self, even in a culture where the presumed bias would be on how the self is solitary and unique. Clearly, this indicates that even those who live in an independent culture value connectedness with others to such a point that other people become part of one's self-concept.

A number of lines of work have considered the interrelations between others and the self. Indeed, concepts such as "attachment," "interdependent self-construal," and "inclusion of other in the self" suggest (at least, metaphorically) that important 
others are connected to, rather than separate from, the self (e.g., Andersen \& Chen, 2002; Aron, Aron, \& Smollan, 1992; Cross \& Madson, 1997; Lewin, 1948; Markus \& Kitayama, 1991; McCall, 1974). As an example, one of the most widely used measures of interpersonal interconnectedness is Aron et al.'s (1992) Inclusion of Other in the Self Scale, which asks participants to report their closeness with another using one of seven Venn-like diagrams of overlapping circles ranging from no overlap to almost complete overlap, with greater overlap reflecting more inclusion. Yet how are such relations represented in memory? We propose that important others are often accorded their own self-aspects, and thus they are directly integrated into one's self-concept.

As illustrated in Figure 1, the fact that Rachel possesses a "Mike's girlfriend" self-aspect reflects a considerable degree of inclusion, which was unlikely in the early days of their dating. Moreover, as Mike becomes "more included in the self," the overall accessibility of her "Mike's girlfriend" self-concept should increase, augmenting its influence on her perceptions and behavior. Furthermore, Mike's qualities, attitudes, and mannerisms may become associated with this self-aspect, setting the stage for mimicry effects that help coordinate their interactions together (e.g., Bargh \& Chartrand, 1999; Bavelas, Black, Lemery, \& Mullett, 1986; Cheng \& Chartrand, 2003; LaFrance \& Broadbent, 1976). Indeed, recent work has shown that mimicry effects can be quite context dependent (e.g., van Baaren, Horgan, Chartrand, \& Dijkmans, 2004), which is consistent with their integration in one's self-aspects. Thus, the MSF proposes that an included other would have a devoted self-aspect in memory and that its relative degree of accessibility would correspond to reports of greater inclusion with the self. Furthermore, we would expect that any significant "other entity" could reveal such outcomes, producing self-aspects devoted to other individuals (e.g., brother), nonpersons (e.g., dog owner), groups (e.g., family), social collectives (e.g., Cubs fan), and less tangible social relationships (e.g., child of God).

By adopting the idea that close others will be represented in self-aspects, some intriguing findings in the literature might be reconsidered. For example, it has been forwarded that the activation of close others affects one's perceptions of the self, with much of this work reporting assimilation toward others' traits in one's own self-reports (e.g., Andersen \& Chen, 2002; Aron, Aron, Tudor, \& Nelson, 1991; Dijksterhuis et al., 1998; Gabriel, Carvallo, Dean, Tippin, \& Renaud, 2005). Although this work has been considered evidence of assimilation of the self toward the representation of another, it is also possible that the consideration of a close other for whom one has a self-aspect means that the activation of that relational self-aspect (e.g., one's spouse self-aspect) activates the attributes associated with that relationship-specific self-aspect, which then determines reports of self-relevant attributes. In other words, rather than producing assimilation in one's self-concept, close others may activate relational self-aspects, which in turn directly guide one's self-assessments and behaviors (through invisible context effects, previously noted). This alternative interpretation underscores the differences between a unitary view of the self and viewing the self as being composed of multiple self-aspects. By proposing that "the self is assimilated" by considering a close other, one tacitly assumes a single self-concept "that moves" as a result of priming. The MSF view, in contrast, argues that one has multiple self-aspects and that context (e.g., priming) activates a particular self-aspect that is qualitatively distinct from other self-aspects. Of course, we do not suggest that priming (producing assimilation or contrast effects; see Mussweiler, 2003; Stapel \& Koomen, 2000) cannot alter selfperceptions. Instead, we propose that, at times, apparent assimilation effects may simply reflect the discrete activation of a relational self-aspect.

There may be other means by which close others influence perceptions of the self as well. For example, Cohen and Gunz (2002) demonstrated that members of interdependent cultures (i.e., participants whose parents were born in Asia), in comparison to those from independent cultures (i.e., those whose parents grew up in North America), recalled more personal memories from a third-person perspective than from a firstperson perspective. Similarly, Kitayama, Snibbe, Markus, and Suzuki (2004) found that cognitive dissonance effects were observed for European Americans quite broadly but only for Japanese participants following priming that induced a sense of being evaluated by others. Studies such as these demonstrate how others influence the self in cultures that encourage interdependent self-construals. However, the MSF anticipates these outcomes would be observed for those with more relational self-aspects (even for members of independent cultures) and that influence-of-other effects should be especially likely for the specific others represented in these relational self-aspects. These specific others who become represented in the selfconcept can be important standards for the self, setting the stage for especially strong social comparisons (see Tesser, 1988; Zell \& Alicke, in press).

As noted above, the inclusion of others in the self should not only involve individuals but also apply to larger collections of people. It is interesting that although many theoretical perspectives consider the extent to which people identify with their social groups (e.g., Brewer, 1991; Brewer \& Gardner, 1996; Crocker \& Major, 1989; Deaux, 1993; Major, Quinton, \& Schmader, 2003; Steele, 1997; Tajfel \& Turner, 1986; Turner et al., 1994), far less work has considered how these social identities are represented in memory. One notable exception is research by Smith and colleagues, who demonstrated evidence of associations in memory between the self and one's social in-groups (for romantic partners, see Aron et al., 1992). Smith et al. (1999) found participants were faster in judging whether traits were characteristic of in-group members when they were self-descriptive than when they were not selfdescriptive (also see Smith \& Henry, 1996). We would contend that as one identifies or disidentifies with social groups, these affiliations are often reflected in one's self-aspects. For instance, 
highly accessible identities (e.g., one's religious or cultural heritage) are likely to be reflected in one's self-aspects (e.g., being Jewish). And like any other type of self-aspect, we predict that more central (and more important) social identities would be activated more frequently, resulting in increased accessibility for these self-aspects. Thus, similar to our predictions regarding inclusion of others in self, we anticipate that more accessible social identity self-aspects will correspond to greater perceptions of identification with those social identities. As a result, the MSF provides a means by which one can assess greater social identification in terms of its representation in memory (i.e., its accessibility), and this single mechanism can account for the inclusion of social entities discussed in a number of disparate literatures (e.g., close relationships, intergroup memberships).

On the other hand, disidentification may be achieved by eliminating a self-aspect from one's self-concept. For example, in the face of the pejorative cultural stereotype that African Americans do not excel academically, it has been suggested that many African Americans disidentify with academia in response to racial stigmatization (Crocker \& Major, 1989; Steele, 1997). The MSF would propose that such disidentification would be revealed by African Americans eliminating student self-aspects from their self-concepts. On the other hand, those who continue to identify strongly with a stigmatizing self-aspect and retain it in their self-concept are more likely to suffer the consequences that accompany it, such as experiencing greater stereotype threat (Schmader, 2002). Thus, the MSF provides an approach by which long-standing ideas such as identification and disidentification are captured in terms of representation.

Indeed, the relation between self and group identification may be quite fluid, and the MSF provides useful ways to explain such variability. For example, Shih et al. (1999) conducted a study where Asian American women, who presumably had self-aspects corresponding to their ethnicity and to their gender, served as participants. In the study, either their ethnic or gender self-aspect was primed through a writing task before completing a series of difficult mathematical problems. When their ethnicity was primed, the women did well on the problems (presumably, the activation of their ethnicity led to better performance because the stereotype that "Asians are good at math" became self-relevant and guided their behavior). On the other hand, when their gender was primed, the women performed more poorly on the same problems, reflecting the effect of stereotype threat (i.e., activating a negative self-relevant stereotype can impair performance on problems associated with a stereotype, such as "women are bad at math"; Beilock, Rydell, \& McConnell, 2007; Schmader \& Johns, 2003; Spencer, Steele, \& Quinn, 1999). As previously noted, work in our lab has shown that women facing stereotype threat in math are motivated to adopt positive identities (i.e., activate their student self-aspect instead of their gender self-aspect) when concurrently provided with multiple self-aspect categories, eliminating stereotype threat effects (Rydell et al., 2009). Thus, self-aspects provide a means by which one can manage multiple social identities, allowing context to activate one but not another and producing markedly different behavior from the same individual.

This perspective that social context can differentially activate self-knowledge related to one's social groups is also an important component of the multidimensional model of racial identity (MMRI; for a review, see Sellers, Smith, Shelton, Rowley, \& Chavous, 1998). Specifically, this work proposes that the manner in which racial identity triggers racial salience is through situational cues, which is compatible with how the MSF proposes that context triggers a self-aspect related to one's social group (also see Mischel \& Shoda, 1995). One important recent contribution of the MMRI is exploring the development of racial identity trajectories (e.g., Seaton, Scottham, \& Sellers, 2006; Yip, Seaton, \& Sellers, 2006), which further underscores the importance of considering the development of self-aspects across one's entire lifetime.

Personality and Individual Differences. The MSF not only speaks to underlying processes involving the self but also provides a bridge for thinking about relations between self-concept representation and individual differences. Typically, personality psychologists have been more concerned with documenting meaningful individual differences than with considering how they are represented in memory, whereas other researchers studying the self have often exhibited little interest in individual differences. But despite the emphasis of the MSF on selfconcept organization, it anticipates that personality will be revealed in self-concept representation at two levels of the self.

Self-aspects. We would expect that meaningful individual differences would be reflected in the self-aspects that people possess. For example, people greater in self-monitoring (Snyder, 1974) are more likely to attend to situations that determine which role self is required, and thus we would anticipate that those greater in self-monitoring would report a greater number of role self-aspects. On the other hand, people with a more independent self-construal (Singelis, 1994) should be more likely to report having a "true self." Relatedly, individuals who are greater in interdependence are more likely to emphasize interconnections with others, which may be reflected by having self-aspects that stress orientations toward others. For instance, it has been shown that women are more likely than men to have such an orientation (e.g., Cross \& Madson, 1997), especially for close dyadic relationships (Gabriel \& Gardner, 1999). Thus, we would expect cultural and gender differences in the proportion of relationship self-aspects.

In line with this reasoning, preliminary work in our lab suggests that gender and culture may show such a correspondence. For example, we have found that women (relative to men) and those who endorse relatively greater interdependent self-construals (Singelis, 1994) have a greater proportion of relationship self-aspects. These findings suggest that meaningful individual differences relate to the types of self-aspects 
one possesses. As such, the MSF establishes links between social cognition and personality, affirming the importance of each and the mutual relation between self-concept structure and its content.

Attributes. When considering one's self-relevant attributes, the MSF provides additional insights for our understanding of personality. In the current framework, personality can be viewed as the attributes associated with one's self-aspects. When activated, the set of attributes associated with a particular self-aspect should promote behavioral consistency within that context (Mischel \& Shoda, 1995). Yet some attributes will likely be influential across contexts because they are represented in multiple self-aspects. Thus, the MSF anticipates that consistency will be exhibited by individuals within particular contexts both by the attributes associated with specific selfaspects and more globally by attributes associated with many self-aspects.

Moreover, the MSF proposes that stable individual differences should be exhibited in a number of ways that transcend personality traits, such as in one's physical appearance, social identities, affective responses, and behaviors. Without a doubt, traits play an important role in cross-situational stability (Costa \& McCrae, 1992; Goldberg, 1993), especially in independent cultures (Cousins, 1989; J. G. Miller, 1984, 1986); however, the MSF anticipates that many different types of self-relevant knowledge will promote consistency as well. For example, one's physical appearance, group memberships, and behaviors will encourage stability through processes such as symbolic self-completion (e.g., Wicklund \& Gollwitzer, 1982), behavioral confirmation (e.g., Snyder, Tanke, \& Berscheid, 1977), and stereotype threat (e.g., Steele, 1997). As a result, one's own actions as well as others' responses contribute to coherence for the self in particular, and at times multiple, contexts. Furthermore, the MSF anticipates that such consistency will be realized through a variety of means (e.g., trait expectations, behaviors, physical appearance).

\section{Comparing the MSF to Other Self-Concept Conceptualizations}

Compartmentalization of the self. Work on compartmentalization of the self (e.g., Showers, 1992; Showers \& Zeigler-Hill, 2003) has examined whether one's self-aspects are compartmentalized (i.e., predominantly associated with attributes of a uniform valence - i.e., mostly positive or mostly negative attributes) or integrated (i.e., a mixture of positive and negative attributes). In addition to considering the valence of the attributes within one's self-aspects, this line of research also takes into consideration the importance of one's self-aspects. Overall, it is argued that an interaction of compartmentalization and importance of one's self-aspects predicts affective experiences. For example, in the face of positive life events, a compartmentalized self-concept will enhance positive experiences because presumably activated self-aspects will be primarily associated with positive qualities. On the other hand, when experiencing negative life events, an integrated self-concept will mitigate the consequences of unfortunate occurrences. These two outcomes (i.e., better experiences following positive events for a compartmentalized self-concept and following negative events for an integrative self-concept) have received considerable empirical support (e.g., Showers, 1992; Showers \& Kling, 1996; Showers, Zeigler-Hill, \& Limke, 2006).

When considering the compartmentalization approach from the perspective of the MSF, the MSF offers some distinct advantages while also capturing its attractive features. For example, its consideration of variability in self-aspect accessibility may very well provide the underlying mechanism involved in participants' self-reports of the differential importance of selfaspects reported by Showers and colleagues. Moreover, even though taking into account the distribution of positive and negative attributes among self-aspects may add predictive utility to understanding valence-related outcomes, we contend that considering the distribution of specific attributes among self-aspects brings greater precision. Consider the following situation involving Rachel: She has an unpleasant breakup with her boyfriend, which would be a negative event for a self-aspect exclusively composed of positive attributes. The MSF would anticipate the dissolution of her relationship would affect the attributes associated with this self-aspect, which could also have implications for her views of herself as a daughter $(40 \%$ of its attributes are associated with her relationship-specific self-aspect). Thus, the focus on specific attributes and the selfaspects with which they are associated provides greater predictive precision than focusing only on the distribution of general valence in one's self-aspects. In fact, we believe that findings observed by Showers and colleagues might be even stronger to the extent that one incorporates the greater specificity offered by the MSF.

Self-complexity. Because the genesis of the MSF began with our previous work on self-complexity, it is appropriate to consider what the MSF offers that is new to this literature. Research on self-complexity (for reviews, McConnell \& Strain, 2007; Rafaeli-Mor \& Steinberg, 2002) focuses on the overall complexity of one's self-concept to produce an individual difference variable to predict outcomes ranging from dealing with stress (e.g., Linville, 1987) to effective mental regulation (e.g., Renaud \& McConnell, 2002). In this work, lower self-complexity represents the degree to which one's self-concept is composed of few and relatively similar selfaspects. For example, those lower in self-complexity report stronger affective responses to life events, presumably because the feedback involves a larger proportion of their overall selfconcept and because overlap among attributes allows the feedback to "spill over" to other self-aspects (Linville, 1985).

Although this spillover effect is predicted by the MSF (most directly with Principle 3), the MSF offers additional insights. First, self-complexity research focuses on identifying a single individual difference measure to capture the overall representational nature of the entire self-concept, whereas the MSF 
makes "local" as well as global predictions. For example, the MSF accounts not only for general affective experiences but also for changes in evaluations of specific self-aspects (e.g., Principle 4). In addition, its account for how self-relevant feedback affects overall affect recognizes that accessibility varies across self-aspects and attributes based on recent and frequent use, which adds a dynamic component to self-knowledge that affects behavior and affective experiences. In general, the processes assumed to underlie self-complexity are captured by MSF principles, yet the MSF offers additional predictions not anticipated by self-complexity research while forwarding a more comprehensive account of self-concept representation (e.g., differential accessibility of self-aspects and attributes).

More generally, the broader applicability of the MSF suggests interesting new directions for self-complexity research. For instance, consider the aforementioned connections between the MSF and self-regulation. In situations where negative affect serves a signaling function in goal attainment (e.g., regulatory focus, cognitive dissonance), new connections between selfcomplexity and goal-directed behavior can be identified. Indeed, recent work in our lab has shown that when one is induced to experience hypocrisy (by acknowledging the importance of good study habits right before recalling specific episodes of poor study preparation), those lower in self-complexity experience strong cognitive dissonance and are especially motivated to change their attitudes about studying because the structure of their self-concept intensifies the experience of hypocrisy (McConnell \& Brown, 2010). Yet this form of attitude change was completely eliminated by providing people with an opportunity to affirm an important personal quality. Thus, this work shows that a classic phenomenon such as cognitive dissonance is influenced by how the self-concept is represented in memory. Other work in our lab inspired by the MSF has identified additional ways to advance and broaden self-complexity research, such as identifying the conditions under which better social support and more desirable personality characteristics promote better well-being (McConnell, Strain, Brown, \& Rydell, 2009) and determining when people are more likely to work harder following failure instead of sidestepping opportunities to practice and prepare for the future (Brown \& McConnell, 2009a).

Mixed-model approaches to the self. One productive line of research has advocated a mixed-model account of self-concept representation (e.g., Klein et al., 1992; Klein et al., 1996; Klein et al., 1999). This perspective proposes that initial selfknowledge is represented as behavioral episodes, but as one's experiences in a behavioral domain increase, the primary unit of self-knowledge becomes trait summaries (Kihlstrom \& Klein, 1994). This body of work has employed very clever priming methodologies to provide support for this position, and the findings parallel work in the person memory literature showing that it takes a number of behavioral episodes before trait-based expectancies emerge in impression formation (Srull \& Wyer, 1989).
The MSF incorporates these features into its account of self-concept representation. For example, exemplars (e.g., events, behaviors) are at the base of self-knowledge, and it is proposed that over time the accumulation of exemplars results in more abstract forms of self-knowledge. However, unlike the mixed-model perspective, the MSF anticipates that abstracted information about the self extends beyond just traits. As previously noted, we contend that attributes are composed of many types of self-knowledge, including behaviors, emotions, affective responses, social categories, and physical features as well (Carlston, 1994; Schleicher \& McConnell, 2005). Furthermore, traits should play a less central role for the self in interdependent cultures (J. G. Miller, 1984). Thus, the MSF is completely compatible with the key features of mixed models of the self, but it proposes that abstract self-knowledge comes in many forms other than personality traits.

Cognitive-affective processing system theory. Finally, there has been recent attention given to how the self might be represented in a connectionist framework, especially by Mischel and colleagues (e.g., Mischel \& Morf, 2003; Mischel \& Shoda, 1995, 1998), who have proposed that the self is composed of a number of cognition-affect units in a connectionist framework. Although connectionist models provide some distinct advantages such as neural plausibility (e.g., McClelland, McNaughton, \& O'Reilly, 1995), it is unclear at this point how compelling the existent evidence is in support of this perspective on the self. For example, the primary piece of supportive evidence provided is that people seem to exhibit "if ... then ..." situation-behavior relations (e.g., Mendoza-Denton et al., 2001). Although such findings are compatible with a connectionist approach, they do not mandate one and can be explained by many accounts (e.g., Nosofsky, Palmeri, \& McKinley, 1994), including the MSF (as previously explained). Furthermore, the choice to establish the basic unit of this model as mental-emotional representations raises questions. What constitutes cognitiveaffective representations? Are experiences without strong affect disqualified from self-knowledge? Also, because knowledge in a connectionist model is derived from the pattern of activation across processing units, what is the value of proposing that processing units are cognitive-affective representations specifically? Admittedly, all new frameworks require time to establish findings that demonstrate their advantages, but at present the MSF can account for situation-behavior relations by considering how the activation of self-aspects (i.e., situation) can produce a variety of outcomes that are even broader than those anticipated by this connectionist approach.

\section{Conclusion}

The MSF provides an account of self-concept representation that emphasizes the importance of one's multiple, contextdependent self-aspects in determining one's experiences and behavior. This framework generates five principles, supported by recent data, which explain a number of phenomena such 
as how self-relevant feedback is experienced and how it influences self-evaluation. By considering the organization of selfaspects and attributes within an associative network, new predictions are advanced as well. For example, self-aspects filter life events, producing an invisible context that affects one's experiences and behaviors. Not only do these invisible contexts have significant implications for behavior, but also they raise important questions about how researchers should assess the self. The MSF also proposes that chronicity may be more circumscribed than previously believed and that selfconcept representation modulates the experience of affect, which has substantial implications for a number of psychological phenomena. In addition to these new insights, the MSF helps integrate a number of diverse literatures, including self-regulation, stability and variability for the self, self-relevant emotions, the integration of others into the self, and many individual difference factors as well. Within each of these literatures, a number of productive lines of work sit in relative isolation from each other. However, the emphasis of the MSF on self-concept representation provides unifying bridges between them. In sum, the MSF presents a common stage on which to address the interplay of many perspectives on the self, integrating a number of traditions that sometimes seem in conflict about the self in social psychology, cultural psychology, personality research, cognitive psychology, and developmental psychology.

\section{Acknowledgments}

The author thanks Christina Brown, John Cacioppo, Shinobu Kitayama, Robert Rydell, Tonya Shoda, Rick Shweder, Eliot Smith, and Penny Visser for their comments on this article.

\section{Declaration of Conflicting Interests}

The author(s) declared no conflicts of interest with respect to the authorship and/or publication of this article.

\section{Financial Disclosure/Funding}

The author(s) received the following financial support for the research and/or authorship of this article: This work supported by National Institute of Mental Health Grant MH068279, National Science Foundation Grant BCS 0601148, and the Lewis Endowed Professorship.

\section{References}

Amiot, C. E., de la Sablonnière, R., Terry, D. J., \& Smith, J. R. (2007). Integration of social identities in the self: Toward a cognitivedevelopmental model. Personality and Social Psychology Review, 11, 364-388.

Andersen, S. M., \& Chen, S. (2002). The relational self: An interpersonal social-cognitive theory. Psychological Review, 109, 619-645.

Anderson, N. H. (1971). Integration theory and attitude change. Psychological Review, 78, 171-206.

Aron, A., Aron, E. N., \& Smollan, D. (1992). Inclusion of Other in the Self Scale and the structure of interpersonal closeness. Journal of Personality and Social Psychology, 63, 596-612.
Aron, A., Aron, E. N., Tudor, M., \& Nelson, G. (1991). Close relationships as including other in the self. Journal of Personality and Social Psychology, 60, 241-253.

Asch, S. E. (1946). Forming impressions of personality. Journal of Abnormal and Social Psychology, 41, 258-290.

Bargh, J. A. (1982). Attention and automaticity in the processing of self-relevant information. Journal of Personality and Social Psychology, 43, 425-436.

Bargh, J. A. (1997). The automaticity of everyday life. In R. S. Wyer (Ed.), Advances in social cognition (Vol. 10, pp. 1-61). Mahwah, NJ: Lawrence Erlbaum.

Bargh, J. A., Bond, R. N., Lombardi, W. J., \& Tota, M. E. (1986). The additive nature of chronic and temporary sources of construct accessibility. Journal of Personality and Social Psychology, 50, 869-878.

Bargh, J. A., \& Chartrand, T. L. (1999). The unbearable automaticity of being. American Psychologist, 54, 462-479.

Bargh, J. A., \& Pratto, F. (1986). Individual construct accessibility and perceptual selection. Journal of Experimental Social Psychology, 22, 293-311.

Baumeister, R. F. (1998). The self. In D. T. Gilbert, S. T. Fiske, \& G. Lindzey (Eds.), Handbook of social psychology (Vol. 1, 4th ed., pp. 680-740). New York, NY: McGraw-Hill.

Baumeister, R. F., \& Leary, M. R. (1995). The need to belong: Desire for interpersonal attachments as a fundamental human motivation. Psychological Bulletin, 117, 497-529.

Bavelas, J. B., Black, A., Lemery, C. R., \& Mullett, J. (1986). "I show how you feel": Motor mimicry as a communicative act. Journal of Personality and Social Psychology, 50, 322-329.

Beilock, S. L., Carr, T. H., MacMahon, C., \& Starkes, J. L. (2002). When paying attention becomes counterproductive: Impact of divided versus skill-focused attention on novice and experienced performance of sensorimotor skills. Journal of Experimental Psychology: Applied, 8, 6-16.

Beilock, S. L., \& Holt, L. E. (2007). Embodied preference judgments: Can likeability be driven by the motor system? Psychological Science, 18, 51-57.

Beilock, S. L., Jellison, W. A., Rydell, R. J., McConnell, A. R., \& Carr, T. H. (2006). On the causal mechanisms of stereotype threat: Can skills that don't rely heavily on working memory still be threatened? Personality and Social Psychology Bulletin, 32, 1059-1071.

Beilock, S. L., Rydell, R. J., \& McConnell, A. R. (2007). Stereotype threat and working memory: Mechanisms, alleviation, and spillover. Journal of Experimental Psychology: General, 136, 256-276.

Bem, D. J. (1967). Self-perception: An alternative interpretation of cognitive dissonance phenomena. Psychological Review, 74, 183-200.

Berglas, S., \& Jones, E. E. (1978). Drug choice as a self-handicapping strategy in response to noncontingent success. Journal of Personality and Social Psychology, 36, 405-417.

Block, J. (1961). Ego-identity, role variability, and adjustment. Journal of Consulting and Clinical Psychology, 25, 392-397. 
Bodenhausen, G. V., Kramer, G. P., \& Suesser, K. (1994). Happiness and stereotypic thinking in social judgment. Journal of Personality and Social Psychology, 66, 621-632.

Bodenhausen, G. V., Macrae, C. N., \& Sherman, J. W. (1999). On the dialectics of discrimination: Dual processes in social stereotyping. In S. Chaiken \& Y. Trope (Eds.), Dual-process theories in social psychology (pp. 271-290). New York, NY: Guilford.

Boldero, J., \& Francis, J. (2000). The relation between selfdiscrepancies and emotion: The moderating roles of self-guide importance, location relevance, and social self-domain centrality. Journal of Personality and Social Psychology, 78, 38-52.

Bower, G. H., \& Forgas, J. P. (2001). Mood and social memory. In J. P. Forgas (Ed.), Handbook of affect and social cognition (pp. 95-120). Mahwah, NJ: Lawrence Erlbaum.

Breckler, S. J., \& Greenwald, A. G. (1986). Motivational facets of the self. In R. M. Sorrentino \& E. T. Higgins (Eds.), Handbook of motivation and cognition: Foundations of social behavior (pp. 145-164). New York, NY: Guilford.

Brewer, M. B. (1991). The social self: On being the same and different at the same time. Personality and Social Psychology Bulletin, 17, 475-482.

Brewer, M. B., \& Gardner, W. (1996). Who is this "we"? Levels of collective identity and self representations. Journal of Personality and Social Psychology, 71, 83-93.

Brown, C. M., \& McConnell, A. R. (2009a). Effort or escape: Selfconcept structure determines self-regulatory behavior. Self and Identity, 8, 365-377.

Brown, C. M., \& McConnell, A. R. (2009b). When chronic isn't chronic: The moderating role of active self-aspects. Personality and Social Psychology Bulletin, 35, 3-15.

Bruner, J. S. (1957). On perceptual readiness. Psychological Review, 64, 123-152.

Campbell, J. D., Trapnell, P. D., Heine, S. J., Katz, I. M., Lavallee, L. F., \& Lehman, D. R. (1996). Self-concept clarity: Measurement, personality correlates, and cultural boundaries. Journal of Personality and Social Psychology, 70, 141-156.

Cantor, N., \& Kihlstrom, J. F. (1987). Personality and social intelligence. Englewood Cliffs, NJ: Prentice Hall.

Carlston, D. E. (1992). Impression formation and the modular mind: The associated systems theory. In L. L. Martin \& A. Tesser (Eds.), The construction of social judgments (pp. 301-341). Hillsdale, NJ: Lawrence Erlbaum.

Carlston, D. E. (1994). Associated systems theory: A systematic approach to cognitive representations of persons. In R. S. Wyer (Ed.), Advances in social cognition (Vol. 7, pp. 1-78). Hillsdale, NJ: Lawrence Erlbaum.

Carver, C. S. (2001). Self-regulation. In A. Tesser \& N. Schwarz (Eds.), Blackwell handbook of social psychology: Intraindividual processes (pp. 307-328). Oxford, UK: Blackwell.

Carver, C. S. (2003). Self-awareness. In M. R. Leary \& J. P. Tangney (Eds.), Handbook of self and identity (pp. 179-196). New York, NY: Guilford.
Carver, C. S., \& Scheier, M. F. (1998). Attention and self-regulation: A control-theory approach to human behavior. New York, NY: Springer-Verlag.

Cervone, D., \& Shoda, Y. (Eds.). (1999). The coherence of personality: Social-cognitive bases of consistency, variability, and organization. New York, NY: Guilford.

Chaiken, S., \& Baldwin, M. W. (1981). Affective-cognitive consistency and the effect of salient behavioral information on the self-perception of attitudes. Journal of Personality and Social Psychology, 41, 1-12.

Chartrand, T. L., \& Bargh, J. A. (2002). Nonconscious motivations: Their activation, operation, and consequences. In A. Tesser, D. A. Stapel, \& J. V. Wood (Eds.), Self and motivation: Emerging psychological perspectives (pp. 13-41). Washington, DC: American Psychological Association.

Chase, W. G., \& Simon, H. A. (1973). Perception in chess. Cognitive Psychology, 4, 55-81.

Cheng, C. M., \& Chartrand, T. L. (2003). Self-monitoring without awareness: Using mimicry as a nonconscious affiliation strategy. Journal of Personality and Social Psychology, 85, 1170-1179.

Cohen, D. (1998). Culture, social organization, and patterns of violence. Journal of Personality and Social Psychology, 75, 408-419.

Cohen, D., \& Gunz, A. (2002). As seen by the other...: Perspectives on the self in the memories and emotional perceptions of Easterners and Westerners. Psychological Science, 13, 55-59.

Collins, A. M., \& Loftus, E. F. (1975). A spreading activation theory of semantic processing. Psychological Review, 82, 407-428.

Cook, W. L., \& Douglas, E. M. (1998). The looking-glass self in family context: A social relations analysis. Journal of Family Psychology, 12, 299-309.

Cooper, J., \& Fazio, R. H. (1984). A new look at dissonance theory. In L. Berkowitz (Ed.), Advances in experimental social psychology (Vol. 17, pp. 229-266). Orlando, FL: Academic Press.

Correll, J., \& Park, B. (2005). A model of the ingroup as a social resource. Personality and Social Psychology Review, 9, 341-359.

Costa, P. T., \& McCrae, R. R. (1992). Four ways five factors are basic. Personality and Individual Differences, 13, 653-665.

Cousins, S. D. (1989). Culture and self-perception in Japan and the United States. Journal of Personality and Social Psychology, 56, 124-131.

Crocker, J., \& Major, B. (1989). Social stigma and self-esteem: The selfprotective properties of stigma. Psychological Review, 96, 608-630.

Cross, S. E., \& Madson, L. (1997). Models of the self: Self-construals and gender. Psychological Bulletin, 122, 5-37.

Deaux, K. (1993). Reconstructing social identity. Personality and Social Psychology Bulletin, 19, 4-12.

DeSteno, D., \& Salovey, P. (1997). Structural dynamism in the concept of self: A flexible model for a malleable concept. Review of General Psychology, 1, 389-409.

Dijksterhuis, A., \& Bargh, J. A. (2001). The perception-behavior expressway: Automatic effects in social perception on social behavior. In M. Zanna (Ed.), Advances in experimental social psychology (Vol. 33, pp. 1-40). San Diego, CA: Academic Press. 
Dijksterhuis, A., \& Nordgren, L. F. (2006). A theory of unconscious thought. Perspectives on Psychological Science, 1, 95-109.

Dijksterhuis, A., Spears, R., Postmes, T., Stapel, D., Koomen, W., Knippenberg, A. V., \& Scheepers, D. (1998). Seeing one thing and doing another: Contrast effects in automatic behavior. Journal of Personality and Social Psychology, 75, 862-871.

Donahue, E. M., Robins, R. W., Roberts, B. W., \& John, O. P. (1993). The divided self: Concurrent and longitudinal effects of psychological adjustment and social roles on self-concept differentiation. Journal of Personality and Social Psychology, 64, 834-846.

Duval, S., \& Wicklund, R. A. (1972). A theory of objective self awareness. Oxford, UK: Academic Press.

Dweck, C. S. (1999). Self-theories: The role in motivation, personality, and development. Philadelphia, PA: Psychology Press.

Dweck, C. S., \& Leggett, E. L. (1988). A social-cognitive approach to motivation and personality. Psychological Review, 95, 256-273.

Ericsson, K. A., \& Staszewski, J. J. (1989). Skilled memory and expertise: Mechanisms of exceptional performance. In D. Klahr \& K. Kotovsky (Eds.), Complex information processing: The impact of Herbert A. Simon (pp. 235-267). Hillsdale, NJ: Lawrence Erlbaum.

Fazio, R. H. (1987). Self-perception theory: A current perspective. In M. P. Zanna, J. M. Olson, \& C. P. Herman (Eds.), Social influence: The Ontario symposium (Vol. 5, pp. 129-150). Hillsdale, NJ: Lawrence Erlbaum.

Ferguson, M. J. (2007). The automaticity of evaluation. In J. A. Bargh (Ed.), Social psychology and the unconscious: The automaticity of higher mental processes (pp. 219-264). New York, NY: Psychology Press.

Fiske, A. P., Kitayama, S., Markus, H. R., \& Nisbett, R. E. (1998). The cultural matrix of social psychology. In D. T. Gilbert, S. T. Fiske, \& G. Lindzey (Eds.), The handbook of social psychology (Vol. 2, pp. 915-981). New York, NY: McGraw-Hill.

Forgas, J. P., \& Williams, K. D. (Eds.). (2002). The social self: Cognitive, interpersonal, and intergroup perspectives. New York, NY: Psychology Press.

Gabriel, S., Carvallo, M., Dean, K. K., Tippin, B., \& Renaud, J. M. (2005). How I see me depends on how I see we: The role of attachment style in social comparison. Personality and Social Psychology Bulletin, 31, 1561-1572.

Gabriel, S., \& Gardner, W. L. (1999). Are there "his" and "hers" types of independence? The implications of gender differences in collective versus relational interdependence for affect, behavior, and cognition. Journal of Personality and Social Psychology, 77, 642-655.

Gasper, K. (2003). When necessity is the mother of invention: Mood and problem solving. Journal of Experimental Social Psychology, 39, 248-262.

Geertz, C. (1973). The interpretation of cultures. New York, NY: Basic Books.

Goldberg, L. R. (1993). The structure of phenotypic personality traits. American Psychologist, 48, 26-34.

Goldin-Meadow, S. (2003). Hearing gesture: How our hands help us think. Cambridge, MA: Harvard University Press.
Greenwald, A. G. (1980). The totalitarian ego: Fabrication and revision of personal history. American Psychologist, 35, 603-618.

Greenwald, A. G., \& Banaji, M. R. (1989). The self as a memory system: Powerful, but ordinary. Journal of Personality and Social Psychology, 57, 41-54.

Harter, S. (1992). The relationship between perceived competence, affect, and motivational orientation within the classroom: Processes and patterns of change. In A. K. Boggiano \& T. S. Pittman (Eds.), Achievement and motivation: A social-developmental perspective (pp. 77-113). New York, NY: Cambridge University Press.

Hasher, L., \& Zacks, R. T. (1988). Working memory, comprehension, and aging: A review and a new view. In G. H. Bower (Ed.), The psychology of learning and motivation: Advances in research and theory (Vol. 22, pp. 193-225). San Diego, CA: Academic Press.

Hayes-Roth, B. (1977). Evolution of cognitive structures and processes. Psychological Review, 84, 260-278.

Higgins, E. T. (1987). Self-discrepancy: A theory relating self and affect. Psychological Review, 94, 319-340.

Higgins, E. T. (1996). Knowledge activation: Accessibility, applicability, and salience. In E. T. Higgins \& A. W. Kruglanski (Eds.), Social psychology: Handbook of basic principles (pp. 133-168). New York, NY: Guilford.

Higgins, E. T. (1997). Beyond pleasure and pain. American Psychologist, 52, 1280-1300.

Higgins, E. T., Idson, L. C., Freitas, A. L., Spiegel, S., \& Molden, D. C. (2003). Transfer of value from fit. Journal of Personality and Social Psychology, 84, 1140-1153.

Higgins, E. T., King, G. A., \& Mavin, G. H. (1982). Individual construct accessibility and subjective impressions and recall. Journal of Personality and Social Psychology, 43, 35-47.

Higgins, E. T., Rholes, W. S., \& Jones, C. R. (1977). Category accessibility and impression formation. Journal of Experimental Social Psychology, 13, 141-154.

Hinkley, K., \& Andersen, S. M. (1996). The working self-concept in transference: Significant-other activation and self-change. Journal of Personality and Social Psychology, 71, 1279-1295.

Holt, L. E., \& Beilock, S. L. (2006). Expertise and its embodiment: Examining the impact of sensorimotor skill expertise on the representation of action-related text. Psychonomic Bulletin and Review, 13, 697-701.

Howe, M. L., Courage, M. L., \& Edison, S. C. (2003). When autobiographical memory begins. Developmental Review, 23, 471-494.

Hugenberg, K., \& Bodenhausen, G. V. (2004). Category membership moderates the inhibition of social identities. Journal of Experimental Social Psychology, 40, 233-238.

James, W. (1890). The principles of psychology. New York, NY: Henry Holt.

Keltner, D., Ellsworth, P. C., \& Edwards, K. (1993). Beyond simple pessimism: Effects of sadness and anger on social perception. Journal of Personality and Social Psychology, 64, 740-752.

Kihlstrom, J. F., Beer, J. S., \& Klein, S. B. (2003). Self and identity as memory. In M. R. Leary \& J. P. Tangney (Eds.), Handbook of self and identity (pp. 68-90). New York, NY: Guilford. 
Kihlstrom, J. F., \& Klein, S. B. (1994). The self as a knowledge structure. In R. S. Wyer \& T. K. Srull (Eds.), Handbook of social cognition (Vol. 1, 2nd ed., pp. 153-208). Hillsdale, NJ: Lawrence Erlbaum.

Kirsh, D., \& Maglio, P. (1994). On distinguishing epistemic from pragmatic action. Cognitive Science, 18, 513-549.

Kitayama, S., Snibbe, A. C., Markus, H. R., \& Suzuki, T. (2004). Is there any "free" choice? Psychological Science, 15, 527-533.

Klein, S. B., Chan, R. L., \& Loftus, J. (1999). Independence of episodic and semantic self-knowledge: The case from autism. Social Cognition, 17, 413-436.

Klein, S. B., Loftus, J., Trafton, J. G., \& Fuhrman, R. W. (1992). Use of exemplars and abstractions in trait judgments: A model of trait knowledge about the self and others. Journal of Personality and Social Psychology, 63, 739-753.

Klein, S. B., Sherman, J. W., \& Loftus, J. (1996). The role of episodic and semantic memory in the development of trait selfknowledge. Social Cognition, 14, 277-291.

Kohlberg, L. A., \& Kramer, R. (1969). Continuities and discontinuities in childhood and adult moral development. Human Development, 12, 93-120.

Kurzban, R., \& Aktipis, C. A. (2007). Modularity and the social mind: Are psychologists too self-ish? Personality and Social Psychology Review, 11, 131-149.

LaFrance, M., \& Broadbent, M. (1976). Group rapport: Posture sharing as a nonverbal indicator. Group and Organization Studies, 1, 328-333.

Landa, C. E., \& Bybee, J. A. (2007). Adaptive elements of aging: Self-image discrepancy, perfectionism, and eating problems. Developmental Psychology, 43, 83-93.

Lewin, K. (1948). The background of conflict in marriage. In G. Lewin (Ed.), Resolving social conflicts: Selected papers in group dynamics (pp. 84-102). New York, NY: Harper.

Linville, P. W. (1985). Self-complexity and affective extremity: Don't put all of your eggs in one cognitive basket. Social Cognition, 3, 94-120.

Linville, P. W. (1987). Self-complexity as a cognitive buffer against stress-related illness and depression. Journal of Personality and Social Psychology, 52, 663-676.

Major, B., Quinton, W. J., \& Schmader, T. (2003). Attributions to discrimination and self-esteem: Impact of group identification and situational ambiguity. Journal of Experimental Social Psychology, 39, 220-231.

Markus, H. R. (1977). Self-schemata and processing information about the self. Journal of Personality and Social Psychology, 35, 63-78.

Markus, H. R., \& Kitayama, S. (1991). Culture and the self: Implications for cognition, emotion, and motivation. Psychological Review, 98, 224-253.

Markus, H. R., \& Kunda, Z. (1986). Stability and malleability of the self-concept. Journal of Personality and Social Psychology, 51, 858-866.

Markus, H. R., \& Nurius, P. (1986). Possible selves. American Psychologist, 41, 954-969.
Marsh, H. W., \& Ayotte, V. (2003). Do multiple dimensions of selfconcept become more differentiated with age? The differential distinctiveness hypothesis. Journal of Educational Psychology, 95, 687-706.

Marsh, H. W., \& Craven, R. G. (2006). Reciprocal effects of selfconcept and performance from a multidimensional perspective: Beyond seductive pleasure and unidimensional perspectives. Perspectives on Psychological Science, 1, 133-163.

Marsh, H. W., \& Shavelson, R. (1985). Self-concept: Its multifaceted, hierarchical structure. Educational Psychologist, 20, 107-123.

Martin, L. L., Ward, D. W., Achee, J. W., \& Wyer, R. S. (1993). Mood as input: People have to interpret the motivational implications of their moods. Journal of Personality and Social Psychology, 64, 317-326.

McCabe, S. E., Schulenberg, J. E., Johnston, L. D., O’Malley, P. M., Bachman, J. G., \& Kloska, D. D. (2005). Selection and socialization effects of fraternities and sororities on US college student substance use: A multi-cohort national longitudinal study. Addiction, $100,512-524$.

McCall, G. J. (1974). A symbolic interactionist approach to attraction. In T. L. Huston (Ed.), Foundations of interpersonal attraction (pp. 217-231). San Diego, CA: Academic Press.

McClelland, J. L., McNaughton, B. L., \& O'Reilly, R. C. (1995). Why there are complementary learning systems in the hippocampus and neocortex: Insights from successes and failures of connection models of learning and memory. Psychological Review, 102, 419-457.

McConnell, A. R. (2001). Implicit theories: Consequences for social judgments of individuals. Journal of Experimental Social Psychology, 37, 215-227.

McConnell, A. R., \& Brown, C. M. (2010). Dissonance averted: Selfconcept organization moderates the effect of hypocrisy on attitude change. Journal of Experimental Social Psychology, 46, 361-366.

McConnell, A. R., Renaud, J. M., Dean, K. K., Green, S. P., Lamoreaux, M. J., Hall, C. E., \& Rydell, R. J. (2005). Whose self is it anyway? Self-aspect control moderates the relationship between self-complexity and well-being. Journal of Experimental Social Psychology, 41, 1-18.

McConnell, A. R., Rydell, R. J., \& Brown, C. M. (2009). On the experience of self-relevant feedback: How self-concept organization influences affective responses and self-evaluations. Journal of Experimental Social Psychology, 45, 695-707.

McConnell, A. R., Rydell, R. J., \& Leibold, J. M. (2002). Expectations of consistency about the self: Consequences for selfconcept formation. Journal of Experimental Social Psychology, $38,569-585$.

McConnell, A. R., Sherman, S. J., \& Hamilton, D. L. (1994). Online and memory-based aspects of individual and group target judgments. Journal of Personality and Social Psychology, 67, 173-185.

McConnell, A. R., \& Strain, L. M. (2007). Content and structure of the self. In C. Sedikides \& S. Spencer (Eds.), The self in social psychology (pp. 51-72). New York, NY: Psychology Press. 
McConnell, A. R., Strain, L. M., Brown, C. M., \& Rydell, R. J. (2009). The simple life: On the benefits of low self-complexity. Personality and Social Psychology Bulletin, 35, 823-835.

McCrae, R. R. (1994). New goals for trait psychology. Psychological Inquiry, 5, 148-153.

McCrae, R. R., \& Costa, P. T. (1999). A five-factory theory of personality. In L. A. Pervin \& O. P. John (Eds.), Handbook of personality: Theory and research (2nd ed., pp. 139-153). New York, NY: Guilford.

McGuire, W. J., \& McGuire C. V. (1988). Content and process in the experience of the self. In L. Berkowitz (Ed.), Advances in experimental social psychology (Vol. 21, pp. 97-144). New York, NY: Academic Press.

Mead, G. H. (1934). Mind, self and society. Chicago, IL: University of Chicago Press.

Mendoza-Denton, R., Ayduk, O., Mischel, W., Shoda, Y., \& Testa, A. (2001). Person $\times$ situation interactionism in selfencoding (I am ... when . . . ): Implications for affect regulation and social information processing. Journal of Personality and Social Psychology, 80, 533-544.

Miller, J. G. (1984). Culture and the development of everyday social explanation. Journal of Personality and Social Psychology, 46, 961-978.

Miller, J. G. (1986). Early cross-cultural commonalities in social explanation. Developmental Psychology, 22, 514-520.

Miller, R. L., Brickman, P., \& Bolen, D. (1975). Attribution versus persuasion as a means for modifying behavior. Journal of Personality and Social Psychology, 31, 430-441.

Mischel, W. (1973). Toward a cognitive social learning reconceptualization of personality. Psychological Review, 80, 252-283.

Mischel, W., \& Morf, C. C. (2003). The self as a psycho-social dynamic processing system: A meta-perspective on a century of the self in psychology. In M. R. Leary \& J. P. Tangney (Eds.), Handbook of self and identity (pp. 15-43). New York, NY: Guilford.

Mischel, W., \& Shoda, Y. (1995). A cognitive-affective system theory of personality: Reconceptualizing situations, dispositions, dynamics, and invariance in personality structure. Psychological Review, 102, 246-268.

Mischel, W., \& Shoda, Y. (1998). Reconciling processing dynamics and personality dispositions. Annual Review of Psychology, 49, 229-258.

Mussweiler, T. (2003). Comparison processes in social judgment: Mechanisms and consequences. Psychological Review, 110, 472-489.

Mussweiler, T. (2006). Doing is for thinking! Stereotype activation by stereotypic movements. Psychological Science, 17, 17-21.

Neisser, U. (1991). Two perceptually given aspects of the self and their development. Developmental Review, 11, 197-209.

Neisser, U. (1993). The perceived self: Ecological and interpersonal sources of self-knowledge. New York, NY: Cambridge University Press.

Niedenthal, P. M., Barsalou, L. W., Winkielman, P., Krauth-Gruber, S., $\&$ Ric, F. (2005). Embodiment in attitudes, social perception, and emotion. Personality and Social Psychology Review, 9, 184-211.
Niedenthal, P. M., Halberstadt, J. B., \& Innes-Ker, A. H. (1999). Emotional response categorization. Psychological Review, 106, 337-361.

Nisbett, R. E., \& Cohen, D. (1996). Culture of honor: The psychology of violence in the South. Boulder, CO: Westview.

Norenzayan, A., \& Schwarz, N. (1999). Telling what they want to know: Participants tailor causal attributions to researchers' interests. European Journal of Social Psychology, 29, 1011-1020.

Norman, G. R., Brooks, L. R., \& Allen, S. W. (1989). Recall by expert medical practitioners and novices as a record of processing attention. Journal of Experimental Psychology: Learning, Memory, and Cognition, 15, 1166-1174.

Nosofsky, R. M., Palmeri, T. J., \& McKinley, S. C. (1994). Ruleplus-exception model of classification learning. Psychological Review, 101, 53-79.

Pelham, B. W., \& Swann, W. B. (1989). From self-conceptions to self-worth: On the sources and structure of global self-esteem. Journal of Personality and Social Psychology, 57, 672-680.

Pervin, L. A. (1994). A critical analysis of trait theory. Psychological Inquiry, 5, 103-113.

Piaget, J. (1932). The moral judgment of the child. London, UK: Routledge Kegan Paul.

Rafaeli-Mor, E., \& Steinberg, J. (2002). Self-complexity and wellbeing: A review and research synthesis. Personality and Social Psychology Review, 6, 31-58.

Renaud, J. M., \& McConnell, A. R. (2002). Organization of the selfconcept and the suppression of self-relevant thoughts. Journal of Experimental Social Psychology, 38, 79-86.

Renaud, J. M., \& McConnell, A. R. (2007). Wanting to be better but thinking you can't: Implicit theory of personality moderate the impact of self-discrepancies on self-esteem. Self and Identity, $6,41-50$.

Roberts, B. W., \& Donahue, E. M. (1994). One personality, multiple selves: Integrating personality and social roles. Journal of Personality, 62, 199-218.

Robins, R. W., John, O. P., \& Caspi, A. (1998). The typological approach to studying personality development. In R. B. Cairns, L. Bergman, \& J. Kagan (Eds.), Method and models for studying the individual (pp. 135-160). Thousand Oaks, CA: Sage.

Robins, R. W., Norem, J. K., \& Cheek, J. M. (1999). Naturalizing the self. In L. A. Pervin \& O. P. John (Eds.), Handbook of personality: Theory and research (2nd ed., pp. 443-477). New York, NY: Guilford.

Rosenberg, M. (1965). Society and the adolescent self-image. Princeton, NJ: Princeton University Press.

Rosenberg, M. (1979). Conceiving the self. New York, NY: Basic Books.

Ross, L., \& Nisbett, R. E. (1991). The person and the situation: Perspectives of social psychology. New York, NY: McGraw-Hill.

Ryan, R. M., \& Deci, E. L. (2000). Self-determination theory and the facilitation of intrinsic motivation, social development, and well-being. American Psychologist, 55, 68-78.

Rydell, R. J., McConnell, A. R., \& Beilock, S. L. (2009). Multiple social identities and stereotype threat: Imbalance, accessibility, and 
working memory. Journal of Personality and Social Psychology, 96, 949-966.

Salancik, G. R., \& Conway, M. (1975). Attitude inferences from salient and relevant cognitive content about behavior. Journal of Personality and Social Psychology, 32, 829-840.

Salovey, P., Detweiler, J. B., Steward, W. T., \& Bedell, B. T. (2001). Affect and health-relevant cognition. In J. P. Forgas (Ed.), Handbook of affect and social cognition (pp. 344-368). Mahwah, NJ: Lawrence Erlbaum.

Schank, R. C., \& Abelson, R. P. (1977). Scripts, plans, goals and understanding: An inquiry into human knowledge structures. Mahwah, NJ: Lawrence Erlbaum.

Schank, R. C., \& Abelson, R. P. (1995). Knowledge and memory: The real story. In R. S. Wyer (Ed.), Knowledge and memory: The real story (pp. 1-85). Hillsdale, NJ: Lawrence Erlbaum.

Schleicher, D. J., \& McConnell, A. R. (2005). The complexity of self-complexity: An associated systems theory approach. Social Cognition, 23, 387-416.

Schmader, T. (2002). Gender identification moderates stereotype threat effects on women's math performance. Journal of Experimental Social Psychology, 38, 194-201.

Schmader, T., \& Johns, M. (2003). Converging evidence that stereotype threat reduces working memory capacity. Journal of Personality and Social Psychology, 85, 440-452.

Schwarz, N., \& Clore, G. L. (1996). Feelings and phenomenal experiences. In E. T. Higgins \& A. W. Kruglanski (Eds.), Social psychology: Handbook of basic principles (pp. 433-465). New York, NY: Guilford.

Schwarz, N., \& Clore, G. L. (2007). Feelings and phenomenal experiences. In E. T. Higgins \& A. W. Kruglanski (Eds.), Social psychology: Handbook of basic principles (2nd ed., pp. 385-407). New York, NY: Guilford.

Seaton, E. K., Scottham, K. M., \& Sellers, R. M. (2006). The status model of racial identity development in African American adolescents: Evidence of structure, trajectories, and well-being. Child Development, 77, 1416-1426.

Sedikides, C. (1995). Central and peripheral self-conceptions are differentially influenced by mood: Tests of the differential sensitivity hypothesis. Journal of Personality and Social Psychology, 65, 317-338.

Sedikides, C., \& Brewer, M. B. (Eds.). (2001). Individual self, relational self, collective self. Philadelphia, PA: Psychology Press.

Sellers, R. M., Smith, M. A., Shelton, J. N., Rowley, S. A. J., \& Chavous, T. M. (1998). Multidimensional model of racial identity: A reconceptualization of African American racial identity. Personality and Social Psychology Review, 2, 18-39.

Serpe, R. T. (1989). Stability and change in self: A structural symbolic interactionist explanation. Social Psychological Quarterly, 50, 44-55.

Shallice, T. (1972). Dual functions of consciousness. Psychological Review, 79, 383-393.

Shapiro, J. R., \& Neuberg, S. L. (2007). From stereotype threat to stereotype threats: Implications of a multi-threat framework for causes, moderators, mediators, consequences, and interventions. Personality and Social Psychology Review, 11, 107-130.

Shavelson, R. J., Hubner, J. J., \& Stanton, G. C. (1976). Validation of construct interpretations. Review of Educational Psychology, 46, 407-441.

Shih, M., Pittinsky, T. L., \& Ambady, N. (1999). Stereotype susceptibility: Identity salience and shifts in quantitative performance. Psychological Science, 10, 80-83.

Showers, C. (1992). Compartmentalization of positive and negative self-knowledge: Keeping bad apples out of the bunch. Journal of Personality and Social Psychology, 62, 1036-1049.

Showers, C. J., \& Kling, K. C. (1996). Organization of self-knowledge: Implications for recovery from sad mood. Journal of Personality and Social Psychology, 70, 578-590.

Showers, C. J., \& Zeigler-Hill, V. (2003). Organization of selfknowledge: Features, functions, and flexibility. In M. R. Leary \& J. P. Tangney (Eds.), Handbook of self and identity (pp. 47-67). New York, NY: Guilford.

Showers, C. J., Zeigler-Hill, V., \& Limke, A. (2006). Self-structure and childhood maltreatment: Successful compartmentalization and the struggle of integration. Journal of Social and Clinical Psychology, 25, 473-507.

Shweder, R. A., \& Bourne, E. J. (1984). Does the concept of the person vary cross-culturally? In R. A. Shweder \& R. A. LeVine (Eds.), Culture theory: Essays on mind, self, and emotion (pp. 158-199). New York, NY: Cambridge University Press.

Shweder, R. A., Goodnow, J., Hatano, G., LeVine, R. A., Markus, H., \& Miller, P. (1998). The cultural psychology of development: One mind, many mentalities. In W. Damon \& R. M. Lerner (Eds.), Handbook of child psychology: Theoretical models of human development (Vol. 1, 5th ed., pp. 865-937). Hoboken, NJ: John Wiley.

Shweder, R. A., \& Miller, J. G. (1985). The social construction of the person: How is it possible? In K. J. Gergen \& K. E. Davis (Eds.), The social construction of the person (pp. 41-69). New York, NY: Springer-Verlag.

Sinclair, R. C., Mark, M. M., \& Clore, G. L. (1994). Mood-related persuasion depends on (mis)attributions. Social Cognition, 12, 309-326.

Singelis, T. M. (1994). The measurement of independent and interdependent self-construals. Personality and Social Psychology Bulletin, 20, 580-591.

Smith, E. R., Coats, S., \& Walling, D. (1999). Overlapping mental representations of self, in-group, and partner: Further response time evidence and a connectionist model. Personality and Social Psychology Bulletin, 25, 873-882.

Smith, E. R., \& Henry, S. (1996). An in-group becomes part of the self: Response time evidence. Personality and Social Psychology Bulletin, 22, 635-642.

Smith, E. R., \& Queller, S. (2004). Mental representations. In M. B. Brewer \& M. Hewstone (Eds.), Social cognition (pp. 5-27). Malden, MA: Blackwell. 
Smith, E. R., Seger, C. R., \& Mackie, D. M. (2007). Can emotions be truly group-level? Evidence regarding four conceptual criteria. Journal of Personality and Social Psychology, 93, 431-446.

Smith, E. R., \& Semin, G. R. (2004). Socially situated cognition: Cognition in its social context. Advances in Experimental Social Psychology, 36, 53-117.

Smith, E. R., \& Semin, G. R. (2007). Socially situated cognition. Current Directions in Psychological Science, 16, 132-135.

Snyder, M. (1974). The self-monitoring of expressive behavior. Journal of Personality and Social Psychology, 30, 526-537.

Snyder, M., Tanke, E. D., \& Berscheid, E. (1977). Social perception and interpersonal behavior: On the self-fulfilling nature of social stereotypes. Journal of Personality and Social Psychology, 35, 656-666.

Spencer, S. J., Steele, C. M., \& Quinn, D. M. (1999). Stereotype threat and women's math performance. Journal of Experimental Social Psychology, 35, 4-28.

Spencer-Rodgers, J., Williams, M. J., \& Peng, K. (in press). Cultural differences in expectations of change and tolerance for contradictions: A decade of empirical research. Personality and Social Psychology Review.

Srull, T. K. (1981). Person memory: Some tests of associative storage and retrieval models. Journal of Experimental Psychology: Human, Learning, and Memory, 7, 440-463.

Srull, T. K., \& Wyer, R. S. (1989). Person memory and judgment. Psychological Review, 96, 58-83.

Stapel, D. A., \& Koomen, W. (2000). Distinctiveness of others, mutability of selves: Their impact on self-evaluations. Journal of Personality and Social Psychology, 79, 1068-1087.

Steele, C. M. (1997). A threat in the air: How stereotypes shape intellectual identity and performance. American Psychologist, 52, 613-629.

Swann, W. B., Chang-Schneider, C., \& McClarty, K. L. (2007). Do people's self-views matter? Self-concept and self-esteem in everyday life. American Psychologist, 62, 84-94.

Swann, W. B., \& Read, S. J. (1981). Acquiring self-knowledge: The search for feedback that fits. Journal of Personality and Social Psychology, 41, 1119-1128.

Swann, W. B., Rentfrow, P. J., \& Guinn, J. S. (2003). Self-verification: The search for coherence. In M. R. Leary \& J. P. Tangney (Eds.), Handbook of self and identity (pp. 367-383). New York, NY: Guilford.

Tajfel, H., \& Turner, J. C. (1986). The social identity theory of intergroup behavior. In $\mathrm{S}$. Worschel \& W. Austin (Eds.), The psychology of intergroup relations (2nd ed., pp. 7-24). Chicago, IL: Nelson-Hall.
Tesser, A. (1988). Toward a self-evaluation maintenance model of social behavior. In L. Berkowitz (Ed.), Advances in experimental social psychology (Vol. 21, pp. 181-227). New York, NY: Academic Press.

Tice, D. M. (1993). The social motivations of people with low selfesteem. In R. F. Baumeister (Ed.), Self-esteem: The puzzle of low self-regard (pp. 37-53). New York, NY: Plenum.

Trafimow, D., Triandis, H. C., \& Goto, S. G. (1991). Some tests of the distinction between the private self and the collective self. Journal of Personality and Social Psychology, 60, 649-655.

Triandis, H. C. (1989). The self and social behavior in differing cultural contexts. Psychological Review, 96, 506-520.

Turner, J. C., Oakes, P. J., Haslam, S. A., \& McGarty, C. (1994). Self and collective: Cognition and social context. Personality and Social Psychology Bulletin, 20, 454-463.

Twenge, J. M. (2007). The socially excluded self. In C. Sedikides \& S. Spencer (Eds.), The self in social psychology (pp. 311-323). New York, NY: Psychology Press.

van Baaren, R. B., Horgan, T. G., Chartrand, T. L., \& Dijkmans, M. (2004). The forest, the trees, and the chameleon: Context dependence and mimicry. Journal of Personality and Social Psychology, 86, 453-459.

Verplanken, B., \& Holland, R. W. (2002). Motivated decision making: Effects of activation and self-centrality of values on choices and behavior. Journal of Personality and Social Psychology, 82, 434-447.

Watson, D., Clark, L. A., \& Tellegen, A. (1988). Development and validation of brief measures of positive and negative affect: The PANAS scales. Journal of Personality and Social Psychology, 54, 1063-1070.

Wegener, D. T., Petty, R. E., \& Smith, S. M. (1995). Positive mood can increase or decrease message scrutiny: The hedonic contingency view of mood and message processing. Journal of Personality and Social Psychology, 69, 5-15.

Wicklund, R. A., \& Gollwitzer, P. M. (1982). Symbolic self-completion. Hillsdale, NJ: Lawrence Erlbaum.

Wilson, M. (2002). Six views of embodied cognition. Psychonomic Bulletin and Review, 9, 625-636.

Yip, T., Seaton, E. K., \& Sellers, R. M. (2006). African American racial identity across the lifespan: Identity status, identity content, and depressive symptoms. Child Development, 77, 1504-1517.

Zell, E., \& Alicke, M. D. (in press). The local dominance effect in self-evaluation: Evidence and explanations. Personality and Social Psychology Review. 